\title{
Space Aquaculture: Prospects for Raising Aquatic Vertebrates in a Bioregenerative Life-Support System on a Lunar Base
}

\author{
Cyrille Przybyla* \\ MARBEC, Univ Montpellier, CNRS, IFREMER, IRD, Palavas-les-Flots, France
}

The presence of a human community on the Moon or on Mars for long-term residence would require setting up a production unit allowing partial or total food autonomy. One of the major objectives of a bioregenerative life-support system is to provide food sources for crewed missions using in situ resources and converting these into the food necessary to sustain life in space. The nutritive quality of aquatic organisms makes them prospective candidates to supplement the nutrients supplied by photosynthetic organisms already studied in the context of space missions. To this end, it is relevant to study the potential of fish to be the first vertebrate reared in the

OPEN ACCESS

Edited by:

Cyprien Verseux,

University of Bremen, Germany

Reviewed by:

Masahiro Chatani,

Showa University, Japan

Paul B Brown,

Purdue University, United States

${ }^{*}$ Correspondence:

Cyrille Przybyla

Cyrille.przybyla@ifremer.fr

Specialty section:

This article was submitted to

Astrobiology,

a section of the journal

Frontiers in Astronomy and Space

Sciences

Received: 22 April 2021 Accepted: 08 June 2021

Published: 24 June 2021

Citation:

Przybyla C (2021) Space Aquaculture:

Prospects for Raising Aquatic

Vertebrates in a Bioregenerative Life-

Support System on a Lunar Base.

Front. Astron. Space Sci. 8:699097.

doi: 10.3389/fspas.2021.699097 framework of space agriculture. This article investigates the prospects of space aquaculture through an overview of the principal space missions involving fish in low orbit and a detailed presentation of the results to date of the Lunar Hatch program, which is studying the possibility of space aquaculture. A promising avenue is recirculating aquaculture systems and integrated multi-trophic aquaculture, which recycles fish waste to convert it into food. In this sense, the development and application of space aquaculture shares the same objectives with sustainable aquaculture on Earth, and thus could indirectly participate in the preservation of our planet.

Keywords: space exploration, fish, aquaculture, bioregenerative life-support system, European seabass, moon, mars, lunar hatch

\section{INTRODUCTION}

Space agencies are currently considering plans to build bases on the Moon or eventually on Mars, establishing a community of Homo sapiens outside the Earth for the first time. Such a project places humanity at the dawn of an unprecedented adventure, which will involve subsisting in a hostile environment devoid of a local trophic chain of nourishment. Like most Earth's organisms, Homo sapiens is composed predominantly of water. Indeed, water is an essential element for human survival, and its presence on a celestial body is a prerequisite for sustainable settlement there. Beyond this, a balanced nutritional intake (proteins, lipids, and carbohydrates) is necessary for basic needs and daily activity. The provision of essential needs will depend on the population size and the duration of stay, and will also require a technical and economic model that allows the supply of food and water. One promising avenue to respond to this constraint is a bioregenerative life-support system (BLSS), which would allow partial food self-sufficiency by deploying strategies for water recycling, aquaponics, and foodproduction systems. 


\section{Photosynthetic Organisms as Food Sources in a Bioregenerative Life Support System}

From the first plants sent into space in 1960 with Sputnik 2 to the current experiments underway at the International Space Station (ISS), the physiological responses of several terrestrial plants under microgravity conditions have been studied for their potential to develop "astrocultures" intended to feed future residents of a space base (Zabel et al., 2016). The environment for cultivation would be different on the Moon (Zeidler et al., 2017) or on Mars (Bamsey et al., 2009; Kiss, 2014) and plant selection and cultivation strategy would have to be adapted for the available local nutrients. A project led by NASA is running experiments on plants in low orbit in a small plant-growth chamber called Veggie carried on the ISS. In 2015, Veggie provided the first lettuce at an edible size entirely produced in real microgravity conditions (Khodadad et al., 2020). The list of candidate plants for cultivation under BLSS conditions includes more than a dozen species: wheat, rice, soybean, peanuts, sweet pepper, carrots, tomatoes, coriander, lettuce, radish, squash, onion, and garlic (Liu et al., 2008; Paradiso et al., 2012; ElNakhel et al., 2019). These cereals, vegetables, and fruits could provide carbohydrates, phosphorus, pre-vitamin $A$, vitamins $B_{1}$, $\mathrm{B}_{6}, \mathrm{~B}_{9}$, and $\mathrm{C}$; however, the protein and fat provided by vegetal sources are often negligible compared to animal sources.

Aside from terrestrial food candidates, aquatic sources have the capacity to provide nutritional compounds required for balanced health. For example, aquatic cyanobacteria, could be produced in bioreactors to supply biological resources. Cyanobacteria are able to fix carbon dioxide from the exhalation of organisms and transform nitrogen waste from various physiological activities (Baque et al., 2014). These organisms are likely to be easier to cultivate on Mars than on the Moon because of the presence in the Martian atmosphere of carbon dioxide and different forms of nitrogen (Verseux et al., 2016), meaning they would not be dependent on the importation of sources of carbon or carbohydrates to the site as would be the case on the Moon. The most well-known edible photosynthetic cyanobacteria on Earth, Arthrospira platensis (formerly known as spirulina), is a credible candidate for cultivation in space. This food source is the subject of study in the framework of the European MELiSSA project consortium (Lasseur et al., 1996; Poughon et al., 2009) to feed astronauts. Moreover, Arthrospira platensis could be used as an indirect food source for humans by feeding fish such as trout, tilapia or sturgeon (Olvera-Novoa et al., 1998; Palmegiano et al., 2005; Flores et al., 2012). The nutritional contribution of Arthrospira platensis is mainly concentrated in its supply of proteins (Sarma et al., 2008), iron and pigment precursors of vitamin A, and antioxidants (Dartsch, 2008), but it only contains marginal amounts of essential fatty acids ( $\omega 6$ ) and lacks of the polyunsaturated fatty acid $\omega 3$.

Microalgal life forms are another potential food source-they are highly diversified and offer a wide range of physiological strategies and proximate composition. To date, a few microalgae strains have been studied in low orbit for experiments in a space environment, including Sphaerocystis sp., a Chlorophyceae (polar/permafrost green algae), which spent 530 days on a panel outside the ISS in the BIOMEX experiment, in temperatures ranging from $-20^{\circ} \mathrm{C}$ in the dark to $47.2^{\circ} \mathrm{C}$ in the light (de Vera et al., 2019). Chlorella sp., well described in the scientific literature, is the favored algae species for a space mission. This microalgae, as well as other families of marine and freshwater microalgae, are aquaculture study subjects, in particular for water purification by eliminating dissolved and suspended matter in water (Yang et al., 2019), the fixation and sequestration of carbon dioxide (Guo et al., 2015; Gales et al., 2020), as feed for aquatic invertebrates such as copepods, and also as a food supplement for humans (Hader et al., 2006; Niederwieser et al., 2018; Yang et al., 2019).

Many strains of marine microalgae that can be cultivated in aquaculture offer a complete nutritional contribution of proteins, vitamins and especially PUFA, $\omega 3 / \omega 6$ and alpha-linoleic acid (ALA), the precursor of eicosapentaenoic acid (EPA) and docosahexaenoic acid (DHA), which are essential elements for proper body functioning, in particular for heart health, vision and brain function. These essential fatty acids are not produced directly by the human body: ALA, EPA, DHA sources are mainly provided by the ingestion of marine organisms such as microalgae, shellfish or finfish.

\section{Space Aquaculture: A Relevant Source of Complementary Nutrition}

Resupplying a base in space from Earth on a weekly basis is neither economically nor technologically feasible (a trip to the Moon takes 4-7 days, and to Mars 5-8 months). A short-term solution is to provide processed and prepackaged space food. However, lyophilized conservation is unstable, especially concerning essential nutrients such as potassium, calcium, vitamin $\mathrm{D}$, and vitamin $\mathrm{K}$, which is involved in muscle and bone maintenance. The micronutrients most sensitive to storage degradation are vitamins $\mathrm{A}, \mathrm{C}, \mathrm{B}_{1}$, and $\mathrm{B}_{6}$ after one year at ambient temperature (Cooper et al., 2017). A possible nutrition strategy for space bases could be to couple local fresh production with supplies brought by cargo spaceships.

Providing fresh, nutritious and safe food is imperative for the success of a manned base on Moon or Mars. Recent studies have shown that food energy needs during a spaceflight are similar to those required on Earth. If energy intake is reduced, the human body is subjected to physiological stress causing cardiovascular deconditioning, bone demineralization, muscle atrophy and immune system deficiency. Moreover, microgravity exposure reduces the nitrogen balance in an astronaut's body. This results in a $30 \%$ reduction in protein synthesis (Stein, 2001). A study of previous manned missions in low orbit monitored the crew's physical performance consuming food commonly used in space missions and showed that an increase in carbohydrates (from plants) and a decrease in animal protein and fat can disturb the diet balance (Gretebeck et al., 1994). Ideally, a fresh animal-based food source should be included in the diet of space residents.

Seafood is one of the healthier animal products for human nutrition. Its nutritional merits and protective benefits have been abundantly described over the last century. Like wild fish, aquaculture fish sequester digestible proteins and essential amino acids, lipids, including essential polyunsaturated fatty acids (PUFAs), essential vitamins and minerals in their 
TABLE 1 | Micronutrients and human nutritional benefits found in fresh fish (adapted from Tacon et al., 2020).

\begin{tabular}{|c|c|c|}
\hline Nutrient class & Fish nutrients & Human health benefits \\
\hline \multirow[t]{2}{*}{ Proteins } & Amino acids & High digestibility-Muscle repair-Cell, enzyme, hormone composition-Neural and digestive functions \\
\hline & Taurine & Most abundant amino acid in human brain, muscle, retina-Essential for renal, retinal and cardiac activity \\
\hline \multirow[t]{2}{*}{ Lipids } & Phospholipids & Cell membrane regeneration-Energy source for metabolism-EPA precursor \\
\hline & EPA/DHA $(\omega 3)$ & $\begin{array}{l}\text { Blood clotting prevention-Artery flexibility-Anti-inflammatory-Cardiovascular disease protection-Macular degeneration } \\
\text { protection-Cognitive function-Dementia prevention }\end{array}$ \\
\hline \multirow[t]{6}{*}{ Vitamins } & A & Vision-Tissue, skin, bones-Cell communication-Heart, lungs, kidneys-cancer prevention \\
\hline & D & $\begin{array}{l}\text { Calcium, phosphorus absorption and regulation-Bone mineralization, osteoporosis shield-Immune function-Anti- } \\
\text { inflammatory-Hypertension regulation }\end{array}$ \\
\hline & E & Antioxidant-PUFA assimilation-Anti-inflammatory-Immune function-Cancer prevention-Cardiovascular protection \\
\hline & B (Choline) & Neurotransmitter-Mood, memory-Muscle control-Nervous system-Fatty liver prevention \\
\hline & B9 (Folic acid) & $\begin{array}{l}\text { Cell renewal-Brain maintenance-Cardiovascular protection and cancer prevention - Depression risk protection-Cognitive } \\
\text { function }\end{array}$ \\
\hline & B12 & Red blood formation-Neurological function-DNA synthesis-Cardiovascular protection-Cognitive function \\
\hline \multirow[t]{7}{*}{ Minerals } & Calcium & $\begin{array}{l}\text { Bones-Muscle activity-Nerve pulse transmission-Osteoporosis protection-Weight management-Hypertension regulation } \\
\text { and cardiovascular protection }\end{array}$ \\
\hline & Copper & Blood cells-Immune function-Energy production-Cardiovascular disease protection-Dementia-Muscle function \\
\hline & lodine & Thyroid protection from radiation-Protein synthesis-Blood regulation \\
\hline & Iron & Oxygen transportation in blood-Muscle metabolism-Hormone synthesis \\
\hline & Magnesium & Enzymatic and metabolic system-Hypertension regulation-Bone development-Heart rhythm-Osteoporosis prevention \\
\hline & Selenium & Thyroid hormone metabolism-DNA synthesis-Cardiovascular disease prevention \\
\hline & Zinc & Immune function-DNA synthesis-Macular degeneration protection \\
\hline
\end{tabular}

muscles. Vitamins are precursors of molecules that are essential coenzymes for enzyme catalysis. When the synthesis of coenzymes is not included in an organism's genetic heritage (this is the case for Homo sapiens), their natural synthesis must be achieved by the ingestion of living cells. These cells are provided by a diet of plants or animals. In addition to micronutrients, farmed marine, brackish and freshwater fish can sequester ALA (PUFA precursor), EPA or DHA from their diet (Tocher, 2015). Several aquaculture fish have the physiological capability to produce EPA and DHA (ALA chain elongation) and store these essential compounds (Morais et al., 2015; Gregory et al., 2016). The micronutrients commonly found in fish and their health benefits are presented in Table $\mathbf{1}$ (Tacon et al., 2020).

At the beginning of the 1980s, the first study on the possibility of space aquaculture emphasized the shared points between recirculating aquaculture systems (RAS) and BLSS (Hanson, 1983). Yet although aquaculture seems to offer a relevant solution for manned long-term missions (Bluem and Paris, 2003), almost four decades later, no significant innovative solutions have been proposed for space exploration. This may be due to the international strategy of developing low orbit science over the last 30 years with the ISS program, to the detriment of more complex and ambitious projects such as trips to the Moon or Mars involving long-term stays.

\section{Why Raise Aquatic Organisms in Space?}

Hydrogen and oxygen are abundant in the Universe, and water molecules are everywhere in the solar system. Sub-glacial liquid water has been detected on many rocky planets such as Mars, Mercury, and Venus (Liu, 2019; McCubbin and Barnes, 2019). There is evidence of the presence of an internal ocean on icy moons such as Enceladus (Cadek et al., 2016) and Europa (Kalousova et al., 2016). Recent research has indicated the presence of water molecules on rocky exoplanets from other solar systems in our galaxy (Olson et al., 2020). Water is the main in situ resource required for a planetary mission, both for longterm human settlement or astrobiology considerations; however, most observations have revealed that this water has high mineral content or is close to brine due to geological mineralization (Orosei et al., 2018). It would need to be purified to use as a source for water of drinking quality, yet it could be primarily used for rearing marine organisms such as algae, invertebrates, or fish.

Today, producing protein from farmed animals (poultry, cattle, or sheep) in low gravity does not seem feasible. A large surface area is needed for livestock rearing, which would directly compete with human space, and costly synthetized air reconditioned from precious in situ resources such as lunar or planetary water or gas produced by BLSS biotechnology would be reserved for the human residents' artificial atmosphere. Due to their poikilothermic physiology, fish require five to twenty times less energy than mammals, and around three times less oxygen, as well as generate less carbon dioxide emissions, which is an important consideration for BLSS gas exchange management.

Another issue is waste management. With terrestrial animals such as pigs, chickens, goats, or cows, feces collection is not easy to solve. However, in aquatic vertebrate production, all dissolved compounds and particulate matter are sequestered in the water and can be easily treated and removed from the system or converted by another organism.

Lastly, compared to terrestrial farmed animals, aquaculture is commonly viewed as playing a major role in improving global food security on Earth because the feed conversion ratio (FCR: the feed biomass necessary to provide to a farmed organism to obtain a weight increase of $1 \mathrm{~kg}$ ) for fish is drastically lower than for land vertebrates. The FCR for different aquaculture organisms compared to that of the main farmed land animals is shown in Figure 1. Protein and calorie retention from aquaculture production is comparable to livestock production (Fry et al., 


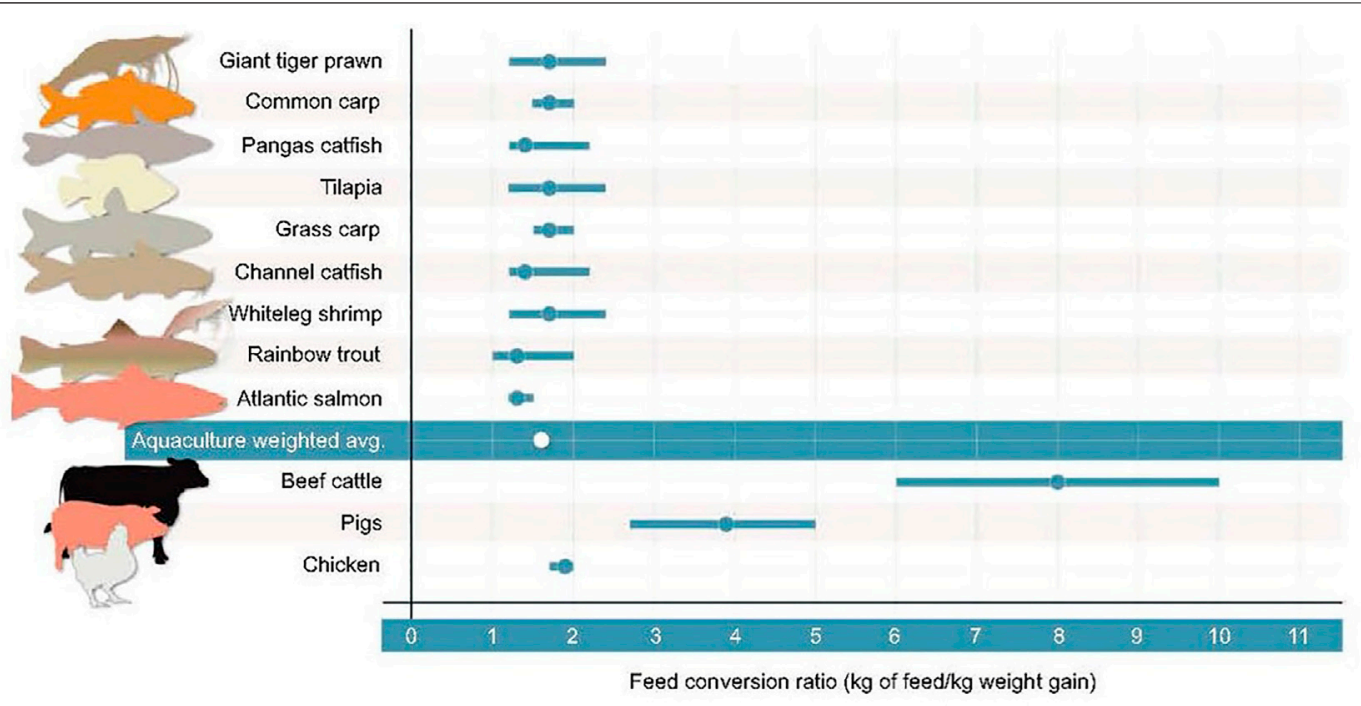

FIGURE 1 | Feed conversion ratios for selected aquaculture species compared to main terrestrial farmed species. Dots represent means and bars indicate the range. Lower values represent higher feed conversion and productivity (from Fry et al., 2018).

2018). All aquatic vertebrates exhibit better feed efficiency, which implies less feed to produce in a BLSS and to manage on the Moon or Mars.

Gas management in lunar or Martian bases will probably be the main challenge for engineers in the next decade. On Earth, the atmosphere sequesters a stock of oxygen, and its continuous production is provided by oceanic and terrestrial photosynthetic organisms. Before the Industrial Revolution, carbon dioxide production was balanced with oxygen consumption. Today, even with the rise in $\mathrm{CO}_{2}$ emissions, oxygen is not a limited source. In contrast, in a closed system in an extreme environment such as the Moon or Mars, oxygen is not available in its basic form and must be produced. Hence, it is a precious molecule and it is of particular interest to include low oxygen consumers-and consequently, low carbon dioxide producers-in a BLSS. Compared to animals that breathe air, fish, and more generally aquatic organisms, have the lowest oxygen requirement and are the lowest producers of carbon dioxide (Figure 2). In fish, carbon dioxide production from respiration is dissolved, concentrated and stored in the water column. Fish have been shown to maintain their oxygen consumption under conditions of elevated $\mathrm{CO}_{2}$ partial pressure (Ishimatsu et al., 2008). The dissolved $\mathrm{CO}_{2}$ from RAS effluent could be used directly by an aquatic photosynthetic organism such as algae. Collecting $\mathrm{CO}_{2}$ emitted from fish and dissolved in the water column and directing it to a secondary biological system without an additive process would be a huge advantage for BLSS gas management.

In contrast to farmed poultry and mammals, aquatic organisms would also be protected from cosmic rays by the water environment, which is an intrinsic radiation shield. The first life forms on Earth developed in a brackish ocean with a salinity of around $10 \mathrm{mg} / \mathrm{L}$ (Quinton, 1912). Complex life emerged from the Earth's oceans when the atmospheric layer had not yet been totally formed by the respiration of

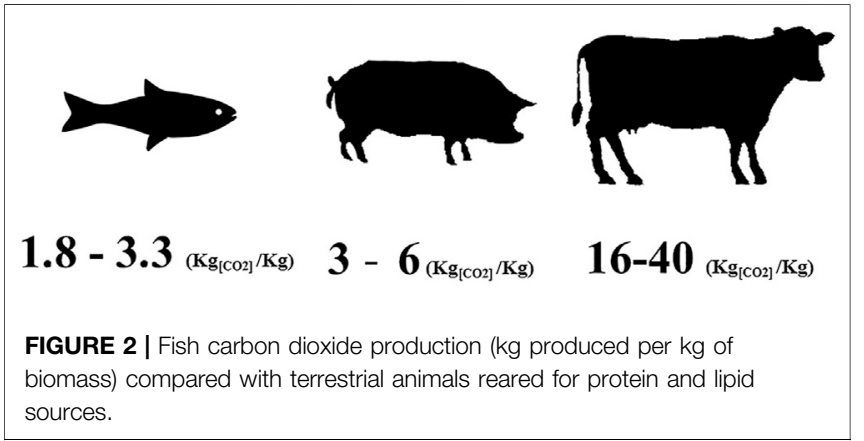

microorganisms (stromatolites, bacteria and microalgae) and volcanic activity. The thin atmosphere exposed the Earth's surface to intense cosmic radiation. The hypothesis that water played a role as a radiation shield in the appearance of aquatic life is strong and plausible. In connection with the development of space aquaculture, further experiments would be needed to determine the integrity or splitting of a heavy charged particle from cosmic radiation entering the water of an aquaculture tank.

Transporting any type of animal in a space mission would subject them for several minutes to hypergravity between 4 and $8 \mathrm{~g}$ (unit of acceleration due to gravity) depending on the space engine. But hypergravity conditions are not unknown for oceanic fish such as the bluefin tuna (Thunnus thynnus). In one stress experiment, the force required for maximal acceleration was measured in this species. The associated hypergravity applied to the tuna was around $3 \mathrm{~g}$ for a few seconds (Dubois et al., 1976). No experiments have been conducted on aquaculture fish, but the natural acceleration caused by an escape behavior has been recorded as between 1 and $3 \mathrm{~g}$.

Another argument in favor of finfish as candidates for space aquaculture is that as opposed to other reared vertebrates and 
humans, in the water column they can move vertically as well as horizontally. Fish use a ballast system, the swim bladder, and otolith sensitivity to move in a volume of water, experiencing gravity but also buoyancy. In the ocean, fish are already in microgravity conditions due to water density and Archimedes' principle. Thus, altered gravity should not interfere with swimming behavior during the lifecycle of a fish. Experiments have revealed that a fish in microgravity during a space mission orients its swimming direction and body position according to the position of the light in the module without losing the ability to feed or affecting social behavior. Fish movement can also be correlated with spaceship rotation (Ibsch et al., 2000; Anken et al., 2002).

Indeed, astronauts train underwater as this is the best way to imitate the weightless conditions found in space. The suits they wear in the training pool are designed to provide neutral buoyancy (like a fish's swim bladder) to simulate the microgravity experienced during spaceflight (Otto F.Trout, 1969). Spaceflight analog missions are conducted underwater in NASA's Extreme Environment Mission Operations (NEEMO), involving multi-hour activities at a depth of $19 \mathrm{~m}$ (Koutnik et al., 2021). While the hypothesis that the variation in space gravity will not drastically disturb the fish from a physical, behavioral or welfare point of view is plausible, this remains to be tested in experiments on aquaculture fish species.

\section{Ornamental Fish as a Model for Understanding Human Physiology in Space}

The zebrafish Danio, the medaka Oryzias, and the swordtail fish Xiphophorus have been frequently boarded on space missions as models for understanding human gravitational sensations, due to the homology with human morphological and physiological systems. These species have proved the most suited vertebrate animals for basic gravity research. The gravity-sensing system in vertebrates from fish to humans has the same basic structure. Although aquarium fish are not aquaculture fish, space missions over the last five decades have provided useful results on fish physiology, behavior and well-being in microgravity (Lychakov, 2016).

The earliest spaceflight with fish occurred on July 28, 1973. Two fingerlings and fifty embryonated eggs of the mummichog (Fundulus heteroclitus) were launched by a Saturn 1B rocket. The Apollo service module joined Skylab 3 and the fish were positioned in a plastic bag filled with seawater. This American space mission preferred the mummichog, a small saltmarsh killifish, to goldfish for this experiment. This species was not well known or described at that time, but it became the first "fishonaut". For three days, swimming in loops and circles was observed for the two fingerlings, but they gradually returned to normal swimming. The fish acclimation period was comparable to that for a human crew during a first spaceflight. This observation suggested that the vestibular function (the otolith for fish-the inner ear for humans) probably plays the same sensory role in microgravity. The Fundulus heteroclitus eggs carried aboard the Skylab station in low orbit hatched successfully during the mission with a very good hatching rate
(96\%). The hatched fry displayed normal swimming behavior in contrast to the first hours in microgravity for the fingerlings (Baumgarten, 1975). Fish embryos in microgravity develop a physiological strategy to compensate for the unusual environment, and the larvae formed were already adapted to microgravity, as evidenced by the lack of looping behavior.

In 1975, during nine days of the manned Apollo-Soyuz MA161 mission, a group of 21-day-old juvenile mummichogs were exposed to real microgravity, and similar irregular swimming was observed. Fish eggs were also boarded ( $n=100 /$ samples at $32 \mathrm{hpf}$ [hours post-fertilization], $66 \mathrm{hpf}$, and $128 \mathrm{hpf}$ stages; pre-liftoff fertilization times) and were subjected to post-flight hatching rate evaluation back on Earth. The juveniles were evaluated using light orientation tests, and no significant differences were observed in behavior, suggesting an adaption capability to the space environment. The embryo hatching rate was $75 \%$, and hatching date monitoring showed that the three earliest stages of egg batches carried on Apollo-Soyuz hatched at 15 days (normal hatching rate is 21 days), much sooner than the latest stage batch and earlier than the control batches at $1 \mathrm{~g}$. Apparently, the development of young eggs was faster under microgravity, but the embryos exhibited no abnormalities resulting from development in a zero-gravity environment. The eyes, heart, nerves, and bones were found to be the same in the flight group as in the control group. There was no evidence of calcium deficiency, except in the shorter hatching-time group (Hoffman et al., 1977).

In July 1994, the 17th Columbia space shuttle mission STS-65 boarded Japanese medaka (Oryzia latipes) for 15 days of spaceflight in the second International Microgravity Laboratory (IML-2). These ornamental fish laid eggs, and normal hatching was observed in space, with the results showing that medaka fertilization and embryonic development was not significantly impaired by altered gravity (Ijiri, 1998).

Probably the most impressive aquatic closed-loop experiment in low orbit and a successful demonstration of an aquatic trophic chain in space, in the 1990s, a German team from Ruhr University Bochum and the German Aerospace Centre (DLR) developed the Closed Equilibrated Biological Aquatic System (CEBAS) with fresh water, containing small aquarium fish (Xiphophorus hellerii), water snails (Biomphalaria glabata), aquatic plants (Ceratophyllum dermersum), and aquatic microorganisms. The ground-based demonstration showed that a filter system was able to keep a closed artificial aquatic ecosystem stable for several months and to eliminate waste products deriving from degraded dead fish without a decrease in oxygen concentration to less than $3.5 \mathrm{mg} / \mathrm{I}$ at $25^{\circ} \mathrm{C}$ (Blum et al., 1994; Blum et al., 1995). Then in January 1998, during the Endeavour space shuttle mission STS-89 to the MIR station, aquarium swordtail fish (Xiphophorus helleri) were exposed to 9 days of microgravity, with 200 juveniles and four pregnant adult fish carried in a mini CEBAS module (10 L) (Blum et al., 1994). The aim of this aquatic mini-module (Figure 3) was to record the behavior of an artificial ecological closed loop in low orbit and verify the hypothesis that aquatic life is not affected by exposure to space conditions using a complementary organism. The female fish were retrieved in good physiological condition, adult and 


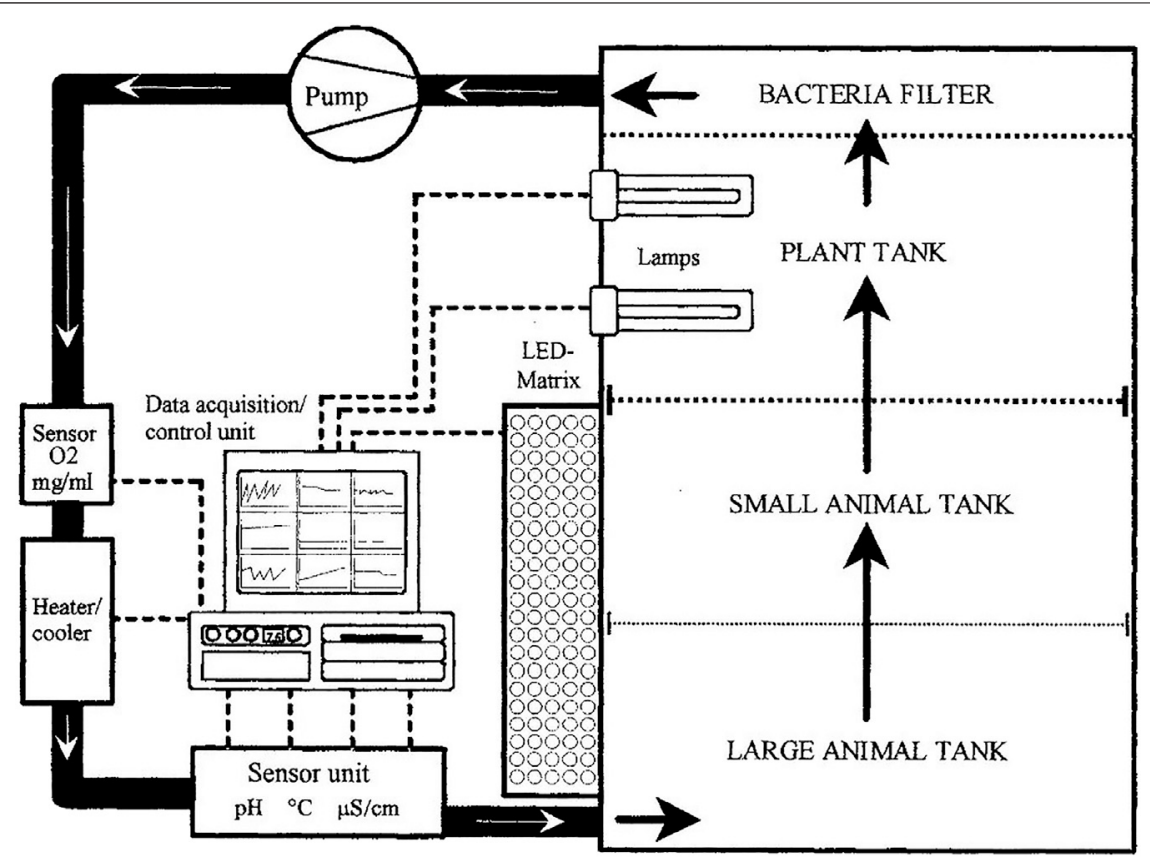

FIGURE 3 | Aquatic CEBAS module diagram demonstrating the trophic chain concept (extract from Bluem et al., 2000).

juvenile fish had a survival rate of about $33 \%$, and almost $97 \%$ of the snails had survived and produced more than 250 neonates in microgravity (Bluem et al., 2000). During the spaceflight, the vertebrates were video-recorded for behavioral analysis and no aberrant looping or spinning behavior was observed. Immediately after landing back on Earth, the adult fish swam vertically, head upward, to the top of their habitat, strongly beating the caudal and pectoral fins. This was due to empty swim bladders not used during the spaceflight and reuse acclimation on Earth (Anken et al., 2000; Bluem et al., 2000; Rahmann and Anken, 2002).

In April 1998, another population of swordtail fish and four adult wild marine fish oyster toadfish (Opsanus tau) flew with the space shuttle STS-90 mission, hosted in the Neurolab facility. After 16 days in real microgravity, fish brain synaptic contacts were compared to a control population at $1 \mathrm{~g}$ on Earth. Spaceflight yielded an increase in synaptic contacts within the vestibular nucleus indicating a compensation processes for neonates swordtail fish (Ibsch et al., 2000). Results revealed a gravity compensation process and the role of the fish lateral line associated to the fish brain for appropriate swimming behavior (Anken et al., 2002).

The Vestibular Function Experiment Unit (VFEU) aboard STS95's SpaceHab again hosted two oyster toadfish as experimental subjects. The fish were electronically monitored to determine the effect of gravitational changes on the otolith system. The freely moving fish provided physiological signals of the otolith nerves. Measurements of afferent and efferent responses were made before, during, and post-flight (Boyle et al., 2001).

In January 2003, four medaka eggs laid on Earth in an artificially controlled environment were launched by the Columbia space shuttle during the STS-107 mission. For the control, four eggs in the same condition remained on the ground. No difference was observed in the time of development. In the ground experiment, the embryos were observed to rotate in the egg membrane, whereas in flight they did not rotate. One egg hatched 8 days after the mission launch in the flight unit, while four eggs hatched in the ground unit. In the flight unit, the fry was observed with its back usually to the camera and little swimming movement suggest. The results shown no appreciable difference in the time course of development between space- and groundbased embryos. (Niihori et al., 2004). The hatched medaka larva, embryos and the crew from the space mission tragically never returned to Earth alive due to the accident during the space shuttle's reentry in the atmosphere.

In 2007, dry eggs of the ornamental killifish the redtail notho (Nothobranchius guentheri) were placed into cotton-cloth bags, then into plastic Petri dishes, and fastened on the outer side of the ISS. The aim of the Biorisk-MSN mission was to expose dry incubated eggs to low orbit radiation. Unfortunately, no data is available concerning the resistance of the fish eggs as the equipment had no temperature sensor and the plastic dishes reached $95^{\circ} \mathrm{C}$, deforming the plates, and the eggs died due to the high temperature and vacuum contact (Baranov et al., 2009).

To study the fish response at early stage to microgravity, two missions using medaka fish were performed on ISS, in 2012 and 2014. Each time a Soyuz rocket sent 24 juveniles medaka ( 6 weeks after hatching, $16 \mathrm{~mm}$ ) with the objective of rearing this population in the Aquatic Habitat (AQH) on the Kibo section of the ISS. Medaka fish in space and control fish from the same family on Earth were filmed. The movies showed that the fish became adapted to life under microgravity although despite an unusual swimming 
TABLE 2 |Studies of ornamental fish used as a physiological model in low orbit missions. References to major missions are noted with numbers in brackets: [1] Baumgarten, 1975; [2] Proshchina, 2021; [3] Hoffman, 1977; [4] ljiri, 1998; [5] Anken, 2000; [6] Anken, 2002; [7] Boyle, 2001; [8] Niihori, 2004; [9] Baranov et al., 2009; [10] Chatani, 2015; Murata, 2015; [11] Chatani, 2016.

\begin{tabular}{|c|c|c|c|c|c|c|c|}
\hline Year & Fish species & Mission & Low orbit station & Duration & Fish stage & Embryos & Study aim \\
\hline 1973 & $\begin{array}{l}\text { Mummichog Fundulus } \\
\text { heteroclitus }\end{array}$ & Apollo ${ }^{[1]}$ CSM-117 & Skylab 3558 orbits & 59 days & $\begin{array}{l}2 \text { fingerlings (post- } \\
\text { hatching) }\end{array}$ & Fish eggs & $\begin{array}{l}\text { Video Hatching and normal } \\
\text { behavior }\end{array}$ \\
\hline 1974 & $\begin{array}{l}\text { Zebrafish Brachidanio } \\
\text { rerio }\end{array}$ & Soyuz $16^{[2]}$ & & $\begin{array}{l}5 \text { days } \\
22 \mathrm{~h}\end{array}$ & - & Five somites & Weightlessness \\
\hline 1975 & $\begin{array}{l}\text { Mummichog Fundulus } \\
\text { heteroclitus }\end{array}$ & $\mathrm{MA}-161^{[3]}$ & Apollo-Soyuz & 9 days & $\begin{array}{l}28 \text { juveniles } \\
\text { ( } 21 \text { days old) }\end{array}$ & $\begin{array}{l}32,66,128,216 \\
336 \text { hpf }\end{array}$ & $\begin{array}{l}\text { Return } \\
\text { Hatching and behavior analysis }\end{array}$ \\
\hline 1975 & $\begin{array}{l}\text { Mummichog Fundulus } \\
\text { heteroclitus }\end{array}$ & Cosmo782 [2] & Bion & 19 days & - & Fish eggs & Fixation after landing \\
\hline 1976 & $\begin{array}{l}\text { Zebrafish Brachidanio } \\
\text { rerio }\end{array}$ & Soyuz $21^{[2]}$ & Salyut 5 & 7.5 days & - & Medium gastrula & Fixation after landing \\
\hline 1976 & $\begin{array}{l}\text { Zebrafish Brachidanio } \\
\text { rerio }\end{array}$ & Soyuz $22^{[2]}$ & Salyut 5 & 49 days & - & Late gastrula & Fixation weightlessness \\
\hline 1994 & Medaka Oryzias latipes & STS-65 ${ }^{[4]}$ Columbia & IML-2 & 15 days & $\begin{array}{l}4 \text { adults } \\
\text { Fertilization in } \\
\text { space }\end{array}$ & $\begin{array}{l}43 \text { laid eggs, } 8 \\
\text { hatched }\end{array}$ & 30 hatched after landing \\
\hline 1998 & $\begin{array}{l}\text { Swordtail fish } \\
\text { Xiphophorus helleri }\end{array}$ & $\begin{array}{l}\text { STS-89 } \\
\text { Endeavour }\end{array}$ & MIR & 8 days & $\begin{array}{l}4 \text { pregnant adults } \\
200 \text { juveniles }\end{array}$ & - & Video-Return-behavior \\
\hline 1998 & $\begin{array}{l}\text { Swordtail fish } \\
\text { Oyster toadfish } \\
\text { Opsanus tau }\end{array}$ & STS-90 ${ }^{[6]}$ Columbia & Neurolab CEBAS & 16 days & $\begin{array}{l}4 \text { toadfish } \\
150-700 \mathrm{~g}\end{array}$ & - & $\begin{array}{l}\text { Vestibular compensation } \\
\text { Synapse formation }\end{array}$ \\
\hline 1998 & $\begin{array}{l}\text { Oyster toadfish } \\
\text { Opsanus tau }\end{array}$ & $\begin{array}{l}\text { STS-95 }{ }^{[7]} \\
\text { Discovery }\end{array}$ & SpaceHab & 9 days & 2 adults & - & $\begin{array}{l}\text { Vestibular monitoring while } \\
\text { swimming }\end{array}$ \\
\hline 2003 & $\begin{array}{l}\text { Medaka } \\
\text { Oryzias latipes }\end{array}$ & $\begin{array}{l}\text { STS } 107^{[8]} \\
\text { Columbia }\end{array}$ & $\begin{array}{l}\text { AHAB } \\
\text { Aquatic habitat }\end{array}$ & & & $\begin{array}{l}4 \text { embryonated } \\
\text { eggs }\end{array}$ & Hatching launch +8 days \\
\hline 2007 & $\begin{array}{l}\text { Redtail notho } \\
\text { Nothobranchius } \\
\text { guentheri }\end{array}$ & $\begin{array}{l}\text { Soyuz }^{[9]} \\
\text { BioRisk-MSN }\end{array}$ & ISS & 406 days & - & Dry fertilized eggs & Outside exposure failed \\
\hline 2011 & $\begin{array}{l}\text { Goldenfish } \\
+ \text { Oyster toadfish } \\
\text { Opsanus tau }\end{array}$ & $\begin{array}{l}\text { STS-135 (last } \\
\text { mission) Atlantis }\end{array}$ & $\begin{array}{l}\text { Aquatic animal } \\
\text { experiment unit }\end{array}$ & 12 days & 6 juveniles & Fertilized eggs & Otolith removed-eggs returned \\
\hline 2012 & Medaka Oryzias latipes & $\begin{array}{l}\text { Soyuz } \\
\text { TMA-06M }\end{array}$ & ISS Kibo Module & 60 days & 24 juveniles & - & Fish behavior gene fluo-signals \\
\hline 2014 & Medaka Oryzias latipes & Progress ${ }^{[11]} \mathrm{M}-22 \mathrm{M}$ & ISS Kibo Module & 8 days & 24 larvae & $\begin{array}{l}\text { Hatching in low } \\
\text { orbit }\end{array}$ & Fluorescence microscopy \\
\hline
\end{tabular}

behavior. In addition, a mating behavior was observed under microgravity at day 33 and was not different from that on the Earth, indicating microgravity environment doesn't disturb fish reproduction. The aquarium fish used for this experiment have fluorescent osteoclast cells, which makes them easier to observe. An osteoclast is a type of bone cell that breaks down bone tissue and responsible for bone loss. After 47 days in space, the fish tended to stay still in the tank. After 56 days, the mission fish group had normal growth compared to a terrestrial control. For fish in microgravity impairment of some physiological functions was accompanied by the activity of osteoclasts and a slight decrease in mineral density and vertebral bones. (Chatani et al., 2015; Murata et al., 2015; Chatani et al., 2016). Historical space missions involving ornamental fish are listed in Table 2.

\section{Missions With Aquaculture Fish in Low Orbits}

Very few missions involving aquaculture fish have been carried out to date (Table 3). In one of these, the common carp (Cyprinus carpio)-considered a very important aquaculture species in many countries-was chosen as a model for a sensor motor experiment by Japanese university teams and the Japan Aerospace Exploration Agency (JAXA). Two colored carp (16 months old, $26 \mathrm{~cm}$ and $263-270 \mathrm{~g}$ ) were carried to the American SpaceLab in 1992. One of the two carp was given a labyrinthectomy (the otolith was removed). For both fish, swimming behavior and dorsal light response was studied and compared. As observed during the first space missions with small fish, the normal carp was unstable (associated with a kind of space motion-sickness) for the first three days, then finally recovered its Earth-based swimming behavior. The fish whose otolith was removed two months before showed a normal dorsal light response $22 \mathrm{~h}$ after launch, and disruption for the next two days as with the normal carp. Unfortunately, the recovery process for the fish with the removed otolith could not be evaluated due to a technical issue, but these observations provided evidence of a sensory-motor disorder during the early phase of adaption to microgravity in aquaculture fish (Mori et al., 1996). The change in body weight was monitored from two days before launch to four days after landing. Both fish recorded a weight loss around $12 \%$ in low 
TABLE 3 S Studies of aquaculture fish as models for sensory motor, reflex experiments and trophic chain demonstrations in low orbit missions. References to major missions are noted with numbers in brackets: [12] Mori, 1994 [13] Sebastian, 2001 [14] Anken, 2016.

\begin{tabular}{|c|c|c|c|c|c|c|c|}
\hline Year & Fish species & Mission & $\begin{array}{l}\text { Low orbit } \\
\text { station }\end{array}$ & Duration & Fish stage & Embryos & Study aim \\
\hline 1992 & $\begin{array}{l}\text { Common carp Cyprinus } \\
\text { carpio }\end{array}$ & $\begin{array}{l}\text { STS-47 } \\
\text { Endeavour }\end{array}$ & $\begin{array}{l}\text { Space Lab- } \\
\text { J ML2 }\end{array}$ & 8 days & 2 carp (263-270 g) & - & Sensory motor experiment \\
\hline 1993 & Tilapia O. mossambicus & $\begin{array}{l}\text { STS-55 } \\
\text { Columbia }\end{array}$ & $\begin{array}{l}\text { Space Lab } \\
\text { D-2 }\end{array}$ & 9 days & $\begin{array}{l}\text { Larvae (post- } \\
\text { hatching) }\end{array}$ & - & Vestibuloocular reflex test \\
\hline 1997 & Tilapia O. mossambicus & $\begin{array}{l}\text { STS-84 }{ }^{[13]} \\
\text { Atlantis }\end{array}$ & $\begin{array}{l}\text { MIR } \\
\text { SMM-06 }\end{array}$ & 10 days & $\begin{array}{l}\text { Larvae (post- } \\
\text { hatching) }\end{array}$ & - & Vestibuloocular reflex test-video \\
\hline 2007 & Tilapia O. mossambicus & Soyuz-U ${ }^{[14]}$ & Foton M3 & 12 days & 26 larvae (12 mm) & - & $\begin{array}{l}\text { Video-vestibular organ-enzymatic } \\
\text { activity }\end{array}$ \\
\hline 2013 & Tilapia O. mossambicus & Soyuz $21 a$ & BION-M1 & 30 days & All fish died & - & Equipment failure \\
\hline
\end{tabular}

orbit after 14 days of fasting. No conclusion can be made as a fasting replicate on the ground was not available (Mori et al., 1994).

During space shuttle missions STS-55 (1993) and STS-84 (1997), tilapia Oreochromis mossambicus larvae that had not yet developed the roll-induced static vestibuloocular reflex were exposed to microgravity for 9-10 days. Young larvae (11-14 days after hatching) already exhibited the vestibuloocular reflex on the 1993 mission. Back on Earth, a vestibuloocular reflex test (fish were turned around their longitudinal axis at an angle of 15,30 , and $45^{\circ}$ ) showed that eye movement and reflex were not affected by exposure to microgravity during the two space missions (Sebastian et al., 2001).

The OMEGAHAB (Aquatic Habitat) is a closed artificial ecosystem that was sent into orbit for 13 days on board the Russian satellite FOTON-M3 in 2007. The goal of the mission led by the German Space Agency was to investigate the possibility of designing a trophic chain in real microgravity using the photosynthetic flagellate Euglena gracilis as an oxygen producer and larvae of tilapia Oreochromis mossambicus as a consumer. This freshwater and brackish species is a popular aquaculture fish, with worldwide production of around 15,000 tons per year. In the 2007 experiment, 26 small larvae (approx. $12 \mathrm{~mm}$ in length) in the flagellate aquarium were studied in low orbit to increase knowledge about the development of the vestibular organs and enzymatic activity. The best fish survival rate (42\%) ever achieved in a German experiment was recorded. Conditions of real microgravity during spaceflight induced a larger than normal otolith compared to a control maintained at $1 \mathrm{~g}$. This could result in a difference in the ability to sense gravity (Anken et al., 2016). In a same ground unit, the photosynthetic producers supplied sufficient amounts of oxygen to a fish compartment with 35 larval cichlids (Hader et al., 2006). Historical space missions involving aquaculture fish are listed in Table 3.

\section{Feeding Fish in Space: Integrated Multi-Trophic Aquaculture}

If fish were farmed on a space base, sending aquaculture feed from Earth to Moon or Mars would make no sense from an economic or lifecycle analysis point of view. Aquatic systems contain a large diversity of species with different roles in nutrient cycles and biomass conversion that contribute to ecosystem balance. Photosynthetic organisms (algae, phytoplankton), invertebrates (crustaceans, mollusks, zooplankton), vertebrates (fish, amphibians), and microorganisms interact in a complex trophic web. By associating different complementary species such as fish, filter feeders, detritivores and primary producers, integrated multi-trophic aquaculture (IMTA) provides an innovative possibility for BLSS on the Moon or Mars.

The nutritional profile of fish is closely linked to their diet quality. In aquaculture, this can be easily adjusted by ensuring a fish feed formulation that includes organisms that synthesize or sequester proteins, lipids of interest (e.g., EPA or DHA), vitamins and minerals. These aquatic organisms can be cultivated separately in a chain (from algae to invertebrates to fish) exclusively with fish waste as a fertilizer or using other available waste from human activities, such as exhaled carbon dioxide, space agriculture byproducts, or residents food waste.

In the framework of sustainable aquaculture on Earth, researchers are studying trophic webs using closed or semiclosed aquatic systems that reuse fish nutrients dissolved in the water column or fish fecal matter as a fertilizer or food source for another aquatic organism. In an IMTA system, microalgae or macroalgae cultivation is easy using fish tank effluents, as the N/P ratio fits the requirements of algae: the increasing algae biomass assimilates nitrogen and phosphorus forms (Pagand et al., 2000). To return treated water back to the fish tank, it can be cleaned so it is safe for fish growth and welfare (Mladineo et al., 2010). Moreover, fish farm effluent is a suitable media for cultivating Nannochloropsis gaditana, a marine algae with a high PUFA content (Dourou et al., 2018). Several studies have reported the possibility of feeding aquaculture fish with microalgae (mostly marine) included in the fish feed formulation. Several microalgae strains have been tested successfully (they do not alter growth kinetics or organoleptic quality) with fish feed made up of $20-40 \%$ of microalgae: Crypthecodinium sp., Phaeodactylum sp. (Atalah et al., 2007) and Schizochytrium sp. (Ganuza et al., 2008; Stuart et al., 2021) have been tested for the seabream and amberjack diet; Tetraselmis sp. (Tulli et al., 2012), and Isochrysis sp. (Tibaldi et al., 2015) for European seabass; Nanofrustulum sp. for salmon, common carp and schrimps 
(Kiron et al., 2012); and Tetraselmis sp. and Isochrysis sp. for cod (Walker and Berlinsky, 2011).

The modern feed form for aquaculture fish is dried pellets with less than $10 \%$ moisture. However, a study has shown that feeding fish using a moist formulation, such as algae or aquatic worms, with a water content around that of the natural prey profile in oceans, did not affect fish growth parameters and in fact increased resistance and immune protection (Przybyla et al., 2014). Thus, photosynthetic or invertebrate aquatic organisms produced in a Moon or Mars greenhouse could be fed directly to aquaculture fish with no transformation process. Researchers are exploring these alternatives to preserve wild fish stocks currently used for aquaculture fish feed (e.g., processed into fish meal and fish oil). Other algae sources with higher integration rates in feed formulations are the focus of future studies, while research is also investigating new types of aquatic prey compatible with fish feed, such as jellyfish (Marques et al., 2016).

The algae cultivated in an IMTA system, as well as fish effluent, can also be a feed source for invertebrates, mollusks (Li et al., 2019), and sea cucumbers (Chary et al., 2020). A team from NASA is studying the possibility of using invertebrate production systems to purify water while growing protein-rich species as food/feed sources. Aquatic species such as copepods or mussels should grow rapidly, offer good protein content and have low mass for launch requirements (Brown et al., 2021). In the ocean, copepods and mussels are the favored natural prey of fish (especially seabream) and can be used as live feed for aquaculture fish. This production could also serve as food for the human crew. Thus, aquatic invertebrates and microalgae could play a key role in a trophic chain on a space base.

In a recirculating aquaculture system, particulate matter is composed mainly of feces, mucus and bacterial clusters. This waste is easy to separate and remove from the RAS. Some copepods can use this media as feed, but another invertebrate is being studied for its ability to reduce this particulate matter and convert it into valuable biomass: the aquatic worm (Galasso et al., 2020). Polychaeta are detritivores and can be a feed source of interest for fish. Aquatic worms cultivated in an RAS can convert fecal matter into useful fatty acids for fish feed (Kicklighter et al., 2003; Bischoff et al., 2009; Palmer et al., 2014). Other synergies might also be possible: for example, Caenorhabditis elegans is a small terrestrial nematode already studied in space as a model for ageing in microgravity, as $35 \%$ of C. elegans genes have human homologs (Honda et al., 2014). This nematode could thus be both cultivated and observed in space in a BLSS.

In wild environments on Earth, a fish's diet is composed of its own congener, algae or invertebrates. Ground-based experiments have evaluated Nile tilapia as a bioregenerative sub-process for reducing solid waste potentially encountered in a space aquaculture system (Gonzales, 2009). The Tilapia feed formulation consisted of vegetable, bacterial, or food waste. Sulfur, nitrogen, protein, carbon and lysine content of waste residues were assimilated, sequestered and recycled in Tilapia muscle. Although Tilapia's specific growth rate from population fed with different fibrous waste were widely inferior $\left(1.4-89.8 \mathrm{mg} / \mathrm{day}^{-1}\right)$ compared to the control population $\left(281.6 \mathrm{mg} /\right.$ day $\left.^{-1}\right)$, the Tilapia's survival rate was not different. These results suggest additional research to improve feed formulation composed with fibrous residues (Gonzales and Brown, 2007).

When considering formulating aquaculture fish feed on a space base using exclusively aquatic organisms cultivated in an IMTA system, it is essential to determine the digestive efficiency of the fish feed. A recent study highlighted the extreme flexibility of European seabass to feed formulations without fish meal and fish oil. In the experiment, fish were given several formulations containing $85 \%$ plant sources and $15 \%$ alternative sources (yeast, insects, and processed animal protein or Arthrospira platensis). Zootechnical results showed that three formulations resulted in a growth equal to fish fed with a traditional commercial formulation including a wild fish source. The bacterial community in the fish digestive tract adapted to the new formulation composed of alternative protein and lipid sources, and bacterial diversity was not altered (Perez-Pascual et al., 2020). This plasticity is probably common to other fish species, allowing a promising avenue to test new innovative formulations for aquaculture fish using exclusively BLSS raw matter sources such as cyanobacteria, plants, algae, and invertebrates.

\section{Applicability and Limitations of a Space Aquaculture System}

Like the systems for other types of food sources being studied for a future BLSS, such as those to produce microalgae and higher plants (Tikhomirov et al., 2007), the design of a space aquaculture system (SAS) is subject to various parameters, including the location in the Solar System. The size of the SAS would depend on the number of residents to feed, the other food sources necessary based on nutritionist's recommendations, the space available on the lunar base, water availability and quality, the energy available for this activity, and the duration the BLSS will need to operate. One scenario might be to provide around $250 \mathrm{~g}$ of fish per person per week. The volume of the tank for rearing the fish should also be correlated to the fish growth rate and the frequency at which the fish are harvested. The diversity of fish species allows possibilities to be imagined such as using the area under the floor of the lunar base for flat fish, for example, or a tank that is not connected to the crew's living area.

On the Moon as on Earth, an aquaculture system requires water circulation. While the energy needed to pump water in an SAS with lunar gravity (one-sixth of Earth's gravity) is yet to be defined, maintaining a set water temperature will have an energy cost. Within a window of tolerance depending on the species, fish growth directly depends on the water temperature (Handeland et al., 2008). In a context of 14 days of Sun exposure and 14 days of darkness, the latter period will require warming the water to maintain the growth rate. Thus the thermal profile of the selected species will be one of the parameters to consider. This aspect will have a direct impact on the total energy required for an acceptable growth yield in the SAS.

Although fish have a low oxygen uptake compared to other vertebrates (Figure 2), a regular supply is required. Oxygen dissolution in the water from hydroxyl extraction and oxygen from the regolith and/or from photosynthesis in plants cultivated in the BLSS must be synchronized with the biological demands of the fish. This requires the capacity to regularly collect, store and 
dissolve oxygen in the water column. The oxygen data from the CEBAS experiment on the STS-89 and STS-90 missions was analyzed to model this concept. Results based on the experimental MINI-MODULE (8.6 L) showed different periods of oxygen accumulation and depletion in the aquatic habitat in plants (oxygen producer) and snails (oxygen consumer). Simulations from ground-based models predict the oxygen concentration and can be adapted for other species (Drayer and Howard, 2014). A trend has to be defined between the volume of oxygen instantly available or stored and the demand of aquatic consumers. This highlights the importance of an oxygen buffer tank linked to a feedback control mechanism (possibly remotely controlled from Earth) in case of a lack of oxygen. Another aspect to monitor is bacterial development inside the system. An axenic environment cannot be considered as bacteria play an essential role in all stages of a balanced ecosystem. Yet bacteria activity affects the nutrient budget and oxygen measurement and availability (Konig et al., 2001). All these parameters will drive the size of the SAS and the fish biomass allowed in an extreme environment such as the Moon.

Another issue to consider is aquatic biomass extraction in the space environment. Harvesting cells such as microalgae is a current challenge, today handled using vacuum and flocculation (Barrut et al., 2012). The development of harvesting tools is required for different aquatic organisms in a limited and constrained space. Regardless of the organism, extraction is necessary when the biomass has reached its optimum growth to avoid uncontrolled water degradation and increased oxygen consumption by microorganisms that would endanger fish production.

The time needed for fish management on a lunar base also depends on the size of the SAS. Current technology developed for RAS drastically reduces the time necessary to maintain the system. Most of the tasks can be automated, such as starting and cleaning the biofilter, monitoring water parameters (Konig et al., 2001), and regulating the water. Fish feeding is a timeconsuming task, but this can also be automated. Fish are able to adapt to self-feeding devices (Coves et al., 1998; Di-Poi et al., 2008), which contribute to the social interaction of the population (Chen et al., 2002). As in plant production systems (Bamsey et al., 2009), several automated SAS actions could be carried out remotely from a control room on Earth. A daily routine (visual checking of the system and fish behavior and nonautomated actions) could be considered to involve around $1 \mathrm{~h}$ every $12 \mathrm{~h}$ for a closed loop system composed of 16 tanks $\left(1 \mathrm{~m}^{3}\right)$ and $8 \mathrm{~kg} / \mathrm{m}^{3}$ of fish biomass (based on personal experience).

The energy available to power the SAS will also determine its design. A ground-based greenhouse simulation for food production with lunar constraints is necessary to study and understand gas flow management, organism interactions, and all related parameters necessary to maintain a stable and balanced ecosystem.

\section{Studying the Feasibility of Sending Aquaculture Fish Embryos to the Moon: The Lunar Hatch Program}

In research underway since 2019, the Lunar Hatch program is investigating the feasibility of shipping embryonated aquaculture fish eggs to space for programmed hatching in a lunar BLSS. The hatched larvae would then be fed with local resources and reared until they reached an appropriate size for human consumption. The aim of the study is proof of concept based on experimental data collected first in ground-based trials, followed by test missions in low orbit, and concluding with a real flight to space, perhaps leading to the hatching of the first vertebrate on the Moon.

The program focuses on the viability of European seabass (Dicentrarchus labrax) for such a project, by analyzing the potential effects on embryos of a Moon journey and the associated environmental changes. Water found on celestial bodies in the Solar System have a saline or hypersaline profile. The choice of the European seabass in the Lunar Hatch program was based on the fact it is a marine organism with an appreciated taste, and its physiology and behavior have been abundantly described. A secondary water source for fish aquaculture could also be considered such as recycled water from a greenhouse or non-potable water from technical process or human activities. The diversity of aquaculture fish species allows the appliacation of many potential "fishonauts", depending on the primary or secondary water resource available in situ (fresh or salt water). Other aquaculture species could equally be considered for rearing in space, such as trout, flat fish or shrimp.

As mentioned, in the 1970s, spaceflight tests were carried out at the egg stage with ornamental fish (Table 2). The choice of eggs as the biological stage for space travel is relevant for several reasons. A low volume of water is required for egg incubation, so the initial launch biological payload could be less than $1 \mathrm{~kg}$ for around 900 future larvae. In aquaculture nurseries, European seabass egg density in the water column is around one egg per milliliter. Unlike the larval or adult stages, the embryogenesis phase is suitable for a spaceflight because embryo development does not require human intervention for several days (the duration of embryogenesis depends on the species). Although embryogenesis involves intense metabolic activity for the development of the future larva, the low biomass and the chorion limit catabolite emission as well as the self-pollution of water during the journey. This would allow either long manned spaceflights with no need for maintenance from the crew, or simply the transport of fish eggs using an automated cargo ship.

Compared to normal conditions in land-based aquaculture production, during a spaceflight fish embryos would be initially subjected to atypical acoustic and mechanical vibrations caused by launcher motors and acceleration in the atmosphere. The effects of this are under study in the framework of the Lunar Hatch program (supported by the French National Institute for Ocean Science, Ifremer) using a standard qualification test commonly employed in the space industry. In a recent experiment, a vibration exciter mimicked the conditions of a SOYUZ-2/FREGAT launch on a population of fish embryos (Figure 4).

In this test, two triplicates $(n=300)$ of embryos of aquaculture species (European seabass and meagre in two separate experiments) were submitted to the acoustic and mechanical environment of a launch for $10 \mathrm{~min}$ at one-third and two-thirds of their development. The hatching rate was then compared to a control triplicate $(n=300)$. No significant differences were observed on the hatching rate for either species whatever the 


\section{Lunar Hatch - Launch Vibrations on Fish Embryos (LAUVE) project}

Soyuz launch simulation

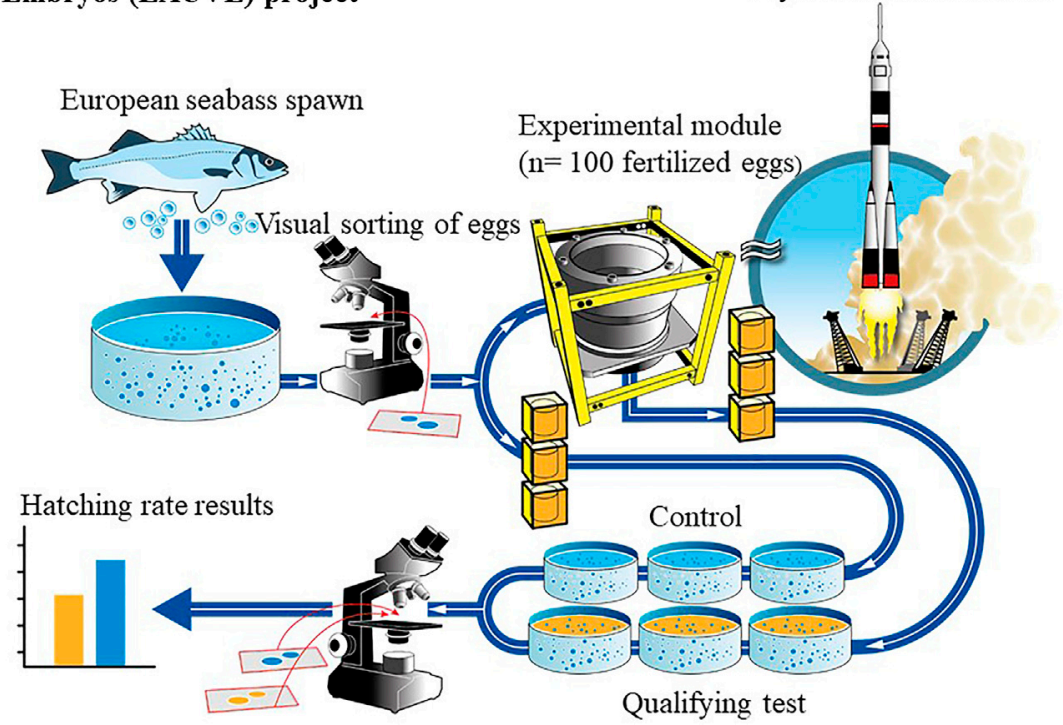

FIGURE 4 | Protocol for the acoustic and mechanical vibrations qualifying test on European seabass embryos (from Przybyla et al., 2020).

stage of development when the embryos were exposed to the conditions (Figure 5).

These encouraging results indicate the egg robustness of two major aquaculture species. A credible hypothesis to explain these results is that the success of the global aquaculture industry is based on the selection of aquatic species for robustness criteria to actions such as unusual and stressful handling-especially at an early lifecycle stage-such as sorting, sampling, transfer from aquarium to tank, or long transport by road or air. The aquaculture sector has selected the most biologically flexible strains with the most interesting nutritional profile for economic reasons. The resulting robustness could benefit space programs-it would not be surprising if other aquaculture species also successfully pass this qualifying test.

Beyond intense vibrations, understanding the influence of hypergravity and microgravity on embryonic development is essential to evaluate the feasibility of space aquaculture. Previous studies on ornamental aquarium fish can provide some information on fish behavior and physiology in space that may be useful.

Hypergravity is experienced during rocket take-off, an acceleration phase that lasts about $10 \mathrm{~min}$ at $4-8 \mathrm{~g}$, depending on the launcher motors. This situation was tested on swordtail fish and medaka otoliths (Anken et al., 1998; Ijiri et al., 2003; Brungs et al., 2011; Anken et al., 2016) and larvae bone development (Aceto et al., 2015; Chatani et al., 2015), but its effects on early ontogeny (hatching capability) are as yet poorly described. A recent research showed that six month exposition at $5 \mathrm{~g}$ can induce vertebral curvatures and asysmetric otoliths (Chatani et al., 2019). However, the duration of exposure to hypergravity during a launch to the Moon or Mars will be about $10 \mathrm{~min}$, the time to extract the embryos from the Earth's attraction. Ongoing experiments are exploring the ability of aquaculture finfish embryos to develop in these conditions. It is credible to posit that hypergravity applied to a water reservoir may be less felt by a submerged embryo. In contrast to poultry eggs stored in air, the water density surrounding fish eggs may reduce the acceleration force on the chorion.

Following the initial conditions of rocket vibrations and acceleration, a situation of microgravity appears beyond an altitude of $110 \mathrm{~km}$. During the entire evolution of life on Earth, the development of all organisms took place under constant gravity conditions in different media (air/water). It should be noted that in the ocean, fish embryos are already in a kind of microgravity compared to terrestrial organisms due to Archimedes' principle and other physical phenomena. This is why, to simulate partial microgravity, astronaut training exercises are carried out in a swimming pool. A study has found that embryos of Xenopus (an aquatic frog) are able to adjust to microgravity environments until hatching through an adaptation mechanism and strategy (Black et al., 1995). Might this capability be common to other aquatic organisms, including fish embryos? Supported by the French space agency (CNES), the Lunar Hatch program plans to study the embryo behavior of European seabass in hypergravity and microgravity in the Gravitational Experimental Platform for Animal Models (GEPAM), a European Space Agency platform to test different gravity environments on animals (Bonnefoy et al., 2021).

Exposure to radiation during the space journey will be the last environmental change investigated in future Lunar Hatch program studies: this is probably the parameter with the most impact on fish embryo biology. Knowledge about the effects of space radiation on a variety of organisms has increased over the last decades: for bacteria (Leys et al., 2009), plant and mammalian cells (Arena et al., 2014), and amphibians (Fuma et al., 2014). A groundbased study on the influence of radiation on fish immediately post-hatching was carried out on the ornamental zebrafish (Danio rerio), in which eggs were irradiated with doses ranging from 1 to $1,000 \mathrm{mSv} . \mathrm{d}^{-1}$ for 20 days (Simon et al., 


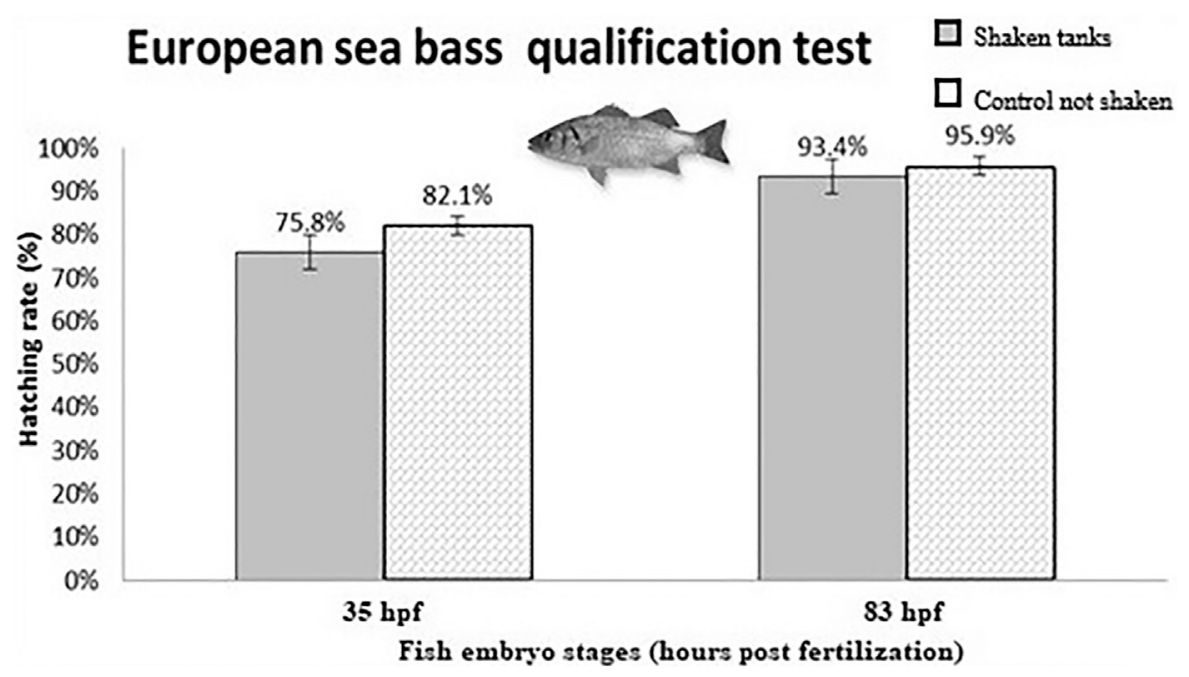

FIGURE 5 | European seabass embryo hatching rate following acoustic and mechanical vibrations from a simulated Soyuz launch qualification test (from Przybyla et al., 2020).

2011). At the stage of 3 days post-hatching, no significant difference in mortality was observed between irradiated eggs and the control. The maximum daily dose was 100 times greater than the total dose astronauts were subjected to during the Apollo 11 mission. These results are consistent with a study in which no significant difference in mortality was observed between $0.8 \mathrm{mGy}$ (the threshold recommended to protect ecosystems) and $570 \mathrm{mGy}$ delivered per day, but the radiation exposure induced accelerated hatching for both doses and a decrease in yolk bag diameter for the highest dose (Gagnaire et al., 2015). In contrast, another study exposing zebrafish embryos to $1,2.5,5,7.5$, and $10 \mathrm{mGy}$ of gamma radiation at $3 \mathrm{hpf}$ showed that increasing gamma radiation increased DNA damage, decreased hatching rate, increased median hatching time, decreased body length, increased mortality rate, and increased morphological deformities (Kumar et al., 2017). A higher total dose but spread over time therefore seems to be less harmful than a single high dose concentrated in the early stages of development. Gagnaire et al. also found abnormal development of the spine for individuals subjected to $570 \mathrm{mGy} \cdot \mathrm{d}^{-1}$. These research results on a small fish provide useful information for countermeasures that would need to be implemented on a lunar base. Fish and crew should be protected to reduce cosmic ray damage. Fish embryos could benefit from progress in countermeasure technology developed for humans, but it would be valuable to conduct experiments on the impact of different particles and charges (separate and cumulative) from cosmic radiation on the candidate fish.

\section{CONCLUSION}

The Lunar Hatch program is investigating the prospects of lunar aquaculture based on a circular food system using a selected species at a specific stage of the lifecycle. It may be of interest to investigate other aquaculture species for other targeted planets or other lifecycle development stages. In the case of the Moon, it is so close to Earth that rearing adults for reproduction would not be worthwhile: a regular shipment of fertilized eggs for monthly generation would avoid costly fish-spawning management on the lunar base. For a more distant destination such as Mars, the embryo stage would be realistic for the first part of the mission, but the total flight would be longer than the duration of embryogenesis. In this case, larval development would need to be considered during the multimonth journey. For farther destinations, studies would need to determine the possibility of rearing broodstock to control the entire biological lifecycle in space.

Space aquaculture would provide a valuable food source in addition to those already studied for long-term missions. The diversity of nutrients provided by fish and the benefits for human metabolism may help in the challenges of space medicine, in particular the prevention of cancer caused by long-term exposure to radiation. The activity of fish farming itself could have positive psychological and cognitive effects. Reports about plant-growth chambers on manned missions have described the psychological benefits of working with living organisms in space. An investigation involving social scientists could be conducted to better understand the possible positive benefits of human-animal interaction in space. Vertebrates may recall basic human activities and provide a psychological umbilical cord with the Earth.

Modern recirculating aquaculture systems share many characteristics with the closed bioregenerative life-support systems planned for space. Progress in aquaculture technology on land and in space can feed into each other. For example, developments that allow space aquaculture systems to recover and convert waste molecules into edible food could be deployed on Earth to increase food availability while avoiding waste discharge in the environment and preserving biodiversity. Joint efforts to design such waste 
conversion systems will be applicable above all to human activities on Earth.

Like other aspects of BLSS, while space aquaculture is close to being a reality, it is highly dependent on the water and energy available in situ. At the turn of the 20th century, the Russian father of astronautic science Konstantin Tsiolkovsky wrote: "Earth is the cradle of humanity, but one cannot remain in a cradle forever." Plants and animals are part of the human biosphere and food chain. Space exploration will likely be more successful if humans leave the cradle with a part of their own biosphere and their knowledge of agricultural science, including aquaculture.

\section{AUTHOR CONTRIBUTIONS}

The author confirms being the sole contributor of this work and has approved it for publication.

\section{FUNDING}

The Lunar Hatch program is supported by the French National Institute for Ocean Science (Ifremer). The author would like to

\section{REFERENCES}

Aceto, J., Nourizadeh-Lillabadi, R., Marée, R., Dardenne, N., Jeanray, N., Wehenkel, L., et al. (2015). Zebrafish Bone and General Physiology Are Differently Affected by Hormones or Changes in Gravity. Plos One 10 (6), e0126928. doi:10.1371/journal.pone.0126928

Anken, R., Brungs, S., Grimm, D., Knie, M., and Hilbig, R. (2016). Fish Inner Ear Otolith Growth under Real Microgravity (Spaceflight) and Clinorotation. Microgravity Sci. Technol. 28 (3), 351-356. doi:10.1007/ s12217-015-9459-4

Anken, R. H., Hilbig, R., Ibsch, M., and Rahmann, H. (2000). "Readaptation of Fish to $1 \mathrm{~g}$ after Long-Term Microgravity: Behavioural Results from the STS 89 mission," in Life Sciences: Microgravity and Space Radiation Effects. Editors K. Slenzka, M. Vazquez, and F. A. Cucinotta, 25, 2019-2023. doi:10.1016/ s0273-1177(99)01009-1

Anken, R. H., Ibsch, M., and Rahmann, H. (2002). "Microgravity (STS-90 Neurolab-Mission) Influences Synapse Formation in a Vestibular Nucleus of Fish Brain," in Space Life Sciences: Biological Research and Space Radiation. Editors K. Ijiri, K. Slenzka, and A. Kronenberg, 30, 843-847. doi:10.1016/s02731177(01)00643-3

Anken, R. H., Ibsch, M., and Rahmann, H. (1998). Neurobiology of Fish under Altered Gravity Conditions. Brain Res. Rev. 28 (1-2), 9-18. doi:10.1016/s01650173(98)00021-6

Arena, C., De Micco, V., Macaeva, E., and Quintens, R. (2014). Space Radiation Effects on Plant and Mammalian Cells. Acta Astronautica 104 (1), 419-431. doi:10.1016/j.actaastro.2014.05.005

Atalah, E., Cruz, C. M. H., Izquierdo, M. S., Rosenlund, G., Caballero, M. J., Valencia, A., et al. (2007). Two Microalgae Crypthecodinium Cohnii and Phaeodactylum Tricornutum as Alternative Source of Essential Fatty Acids in Starter Feeds for Seabream (Sparus aurata). Aquaculture 270 (1-4), 178-185. doi:10.1016/j.aquaculture.2007.04.009

Bamsey, M., Berinstain, A., Graham, T., Neron, P., Giroux, R., Braham, S., et al. (2009). Developing Strategies for Automated Remote Plant Production Systems: Environmental Control and Monitoring of the Arthur Clarke Mars Greenhouse in the Canadian High Arctic. Adv. Space Res. 44 (12), 1367-1381. doi:10.1016/j.asr.2009.08.012 thank Ifremer's scientific directorate, the European and international affairs directorate, and the biological and environmental resources department for supporting and funding the space aquaculture project. The author warmly thanks the technicians, engineers and researchers involved in the project: G. Dutto, B. Rollin, E. Gasset, S. Triplet, E. Mansuy, B. Geffroy, S. Lallemand, and T. Laugier, among others. The Lunar Hatch program is also supported by the French National Centre for Space Studies (CNES), funded under the 2019 and 2020 call for research projects (APR-DAR4800001044). The author warmly thanks G. Gauquelin-Koch, A. Paillet, G. Rabin, and F. Spiero from CNES for their relevant comments and their support.

\section{ACKNOWLEDGMENTS}

The author is also grateful to L. Dusseau and M. Bernard from the University Space Center of Montpellier (CSUM), the historical partners of the Lunar Hatch program, A. Fuchs and V. Ribière for valuable discussions and useful contacts in the space industry, and E. Bradbury for the editorial review of the article.

Baqué, M., Verseux, C., Rabbow, E., de Vera, J.-P. P., and Billi, D. (2014). Detection of Macromolecules in Desert Cyanobacteria Mixed with a Lunar Mineral Analogue after Space Simulations. Orig Life Evol. Biosph. 44 (3), 209-221. doi:10.1007/s11084-014-9367-4

Baranov, V. M., Novikova, N. D., Polikarpov, N. A., Sychev, V. N., Levinskikh, M. A., and Alekseev, V. R. (2009). The Biorisk experiment: 13-month Exposure of Resting Forms of Organism on the Outer Side of the Russian Segment of the International Space Station: Preliminary Results. Doklady Biol. Sci. 426 (1), 267-270. doi:10.1134/s0012496609030223

Barrut, B., Blancheton, J.-P., Champagne, J.-Y., and Grasmick, A. (2012). Water Delivery Capacity of a Vacuum Airlift - Application to Water Recycling in Aquaculture Systems. Aquacultural Eng. 48, 31-39. doi:10.1016/ j.aquaeng.2011.12.010

Baumgarten, v. (1975). Effect of Prolonged Weightlessness on the Swimming Pattern of Fish Aboard Skylab 3. Aviat Sapce Environ. Med. 46 (7), 902-906.

Bischoff, A. A., Fink, P., and Waller, U. (2009). The Fatty Acid Composition of Nereis Diversicolor Cultured in an Integrated Recirculated System: Possible Implications for Aquaculture. Aquaculture 296 (3-4), 271-276. doi:10.1016/ j.aquaculture.2009.09.002

Black, S., Larkin, K., Jacqmotte, N., Wassersug, R., Pronych, S., and Souza, K. (1995). "Regulative Development of Xenopus laevis in Microgravity,". Life and Gravity: Physiological and Morphological Responses. Editors P. Todd, H. J. Anton, P. W. Barlow, R. Gerzer, J. M. Heim, R. HemmersbachKrause, et al.209-217. doi:10.1016/0273-1177(95)00637-t

Bluem, V., Andriske, M., Paris, F., and Voeste, D. (2000). "The C.E.B.A.S.Minimodule: Behaviour of an Artificial Aquatic Ecological System during Spaceflight," in Life Sciences: Space Life Support Systems and the Lunar Farside Crater Saha Proposal. Editors T. W. Tibbitts, R. M. Wheeler, C. A. Mitchell, and J. Heidmann (Oxford: Pergamon Press Ltd)), 26, 253-262. doi:10.1016/s0273-1177(99)00569-4

Bluem, V., and Paris, F. (2003). "Possible Applications of Aquatic Bioregenerative Life Support Modules for Food Production in a Martian Base," in Space Life Sciences: Missions to Mars, Radiation Biology, and Plants as a Foundation for Long-Term Life Support Systems in Space. Editors G. Horneck, M. E. Vazquez, and D. M. Porterfield, 31, 77-86. doi:10.1016/s0273-1177(02)00659-2

Blum, V., Andriske, M., Kreuzberg, K., and Schreibman, M. P. (1995). Animal Protein Production Modules in Biological Life Support Systems: Novel 
Combined Aquaculture Techniques Based on the Closed Equilibrated Biological Aquatic System (CEBAS). Acta Astronautica 36 (8-12), 615-623. doi:10.1016/0094-5765(95)00150-6

Blüm, V., Kreuzberg, K., and Stretzke, E. (1994). “C.E.B.A.S. Mini Module: Test Results of an Artificial (Man-made) Aquatic Ecosystem,". Life Sciences and Space Research Xxv. Editors R. D. MacElroy, C. A. Mitchell, M. Andre, C. C. Blackwell, T. W. Tibbitts, A. Banin, et al. (Oxford: Pergamon Press Ltd)), 14, 89-98. doi:10.1016/0273-1177(94)90284-4

Bonnefoy, J., Ghislin, S., Beyrend, J., Coste, F., Calcagno, G., Lartaud, I., et al. (2021). Gravitational Experimental Platform for Animal Models, a New Platform at ESA's Terrestrial Facilities to Study the Effects of Micro- and Hypergravity on Aquatic and Rodent Animal Models. Ijms 22 (6), 2961. doi:10.3390/ijms22062961

Boyle, R., Mensinger, A. F., Yoshida, K., Usui, S., Intravaia, A., Tricas, T., et al. (2001). Neural Readaptation to Earth's Gravity Following Return from Space. J. Neurophysiol. 86 (4), 2118-2122. doi:10.1152/jn.2001.86.4.2118

Brown, L., Peick, J., Pickett, M., Fanara, T., Gilchrist, S., Smiley, A., et al. (2021). Aquatic Invertebrate Protein Sources for Long-Duration Space Travel. Life Sci. Space Res. 28, 1-10. doi:10.1016/j.lssr.2020.10.002

Brungs, S., Hauslage, J., Hilbig, R., Hemmersbach, R., and Anken, R. (2011). Effects of Simulated Weightlessness on Fish Otolith Growth: Clinostat versus RotatingWall Vessel. Adv. Space Res. 48 (5), 792-798. doi:10.1016/j.asr.2011.04.014

Cadek, O., Tobie, G., Van Hoolst, T., Masse, M., Choblet, G., Lefevre, A., et al. (2016). Enceladus's Internal Ocean and Ice Shell Constrained from Cassini Gravity, Shape, and Libration Data. Geophys. Res. Lett. 43 (11), 5653-5660. doi:10.1002/2016gl068634

Chary, K., Aubin, J., Sadoul, B., Fiandrino, A., Coves, D., and Callier, M. D. (2020). Integrated Multi-Trophic Aquaculture of Red Drum (Sciaenops Ocellatus) and Sea Cucumber (Holothuria Scabra): Assessing Bioremediation and Life-Cycle Impacts. Aquaculture 516:734621 doi:10.1016/j.aquaculture.2019.734621

Chatani, M., Mantoku, A., Takeyama, K., Abduweli, D., Sugamori, Y., Aoki, K., et al. (2015). Microgravity Promotes Osteoclast Activity in Medaka Fish Reared at the International Space Station. Scientific Rep. 5 (1). doi:10.1038/srep14172

Chatani, M., Mitsuhashi, A., Dodo, Y., Sakai, N., and Takami, M. (2019). Hypergravity Induces Vertebrae and Otolith Deformation in Medaka Fish. Biol. Sci. Space 33, 12-17. doi:10.2187/bss.33.12

Chatani, M., Morimoto, H., Takeyama, K., Mantoku, A., Tanigawa, N., Kubota, K., et al. (2016). Acute Transcriptional Up-Regulation Specific to Osteoblasts/ osteoclasts in Medaka Fish Immediately after Exposure to Microgravity. Scientific Rep. 6, 39545. doi:10.1038/srep39545

Chen, W., Naruse, M., and Tabata, M. (2002). The Effect of Social Interactions on Circadian Self-Feeding Rhythms in Rainbow trout Oncorhynchus mykiss Walbaum. Physiol. Behav. 76 (2), 281-287. doi:10.1016/s0031-9384(02)00700-x

Cooper, M., Perchonok, M., and Douglas, G. L. (2017). Initial Assessment of the Nutritional Quality of the Space Food System over Three Years of Ambient Storage. Npj Microgravity 3 (1), 17. doi:10.1038/s41526-017-0022-z

Coves, D., Gasset, E., Lemarie, G., and Dutto, G. (1998). A Simple Way of Avoiding Feed Wastage in European Seabass, under Self-Feeding Conditions. Aquat. Living Resour. 11 (6), 395-401. doi:10.1016/s0990-7440(99)80005-9

Dartsch, P. C. (2008). Antioxidant Potential of selectedSpirulina Platensis Preparations. Phytother. Res. 22 (5), 627-633. doi:10.1002/ptr.2310

de Vera, J.-P., Alawi, M., Backhaus, T., Baqué, M., Billi, D., Böttger, U., et al. (2019). Limits of Life and the Habitability of Mars: The ESA Space Experiment BIOMEX on the ISS. Astrobiology 19 (2), 145-157. doi:10.1089/ast.2018.1897

Di-Poi, C., Beauchaud, M., Bouchut, C., Dutto, G., Covès, D., and Attia, J. (2008). Effects of High Food-Demand Fish Removal in Groups of Juvenile Sea Bass (Dicentrarchus labrax). Can. J. Zool. 86 (9), 1015-1023. doi:10.1139/z08-077

Dourou, M., Tsolcha, O. N., Tekerlekopoulou, A. G., Bokas, D., and Aggelis, G. (2018). Fish Farm Effluents Are Suitable Growth media for Nannochloropsis Gaditana , a Polyunsaturated Fatty Acid Producing Microalga. Eng. Life Sci. 18 (11), 851-860. doi:10.1002/elsc.201800064

Drayer, G. E., and Howard, A. M. (2014). Modeling and Simulation of an Aquatic Habitat for Bioregenerative Life Support Research. Acta Astronautica 93, 138-147. doi:10.1016/j.actaastro.2013.07.013

Dubois, A. B., Cavagna, G. A., and Fox, R. S. (1976). LOCOMOTION OF BLUEFISH. J. Exp. Zool. 195 (2), 223-235. doi:10.1002/jez.1401950207

El-Nakhel, C., Giordano, M., Pannico, A., Carillo, P., Fusco, G. M., Pascale, S., et al. (2019). Cultivar-Specific Performance and Qualitative Descriptors for Butterhead
Salanova Lettuce Produced in Closed Soilless Cultivation as a Candidate Salad Crop for Human Life Support in Space. Life 9 (3), 61. doi:10.3390/life9030061

Flores, G. H., Hernandez, L. H. H., Araiza, M. A. F., and Lopez, O. A. (2012). Effects of Total Replacement of Fishmeal with Spirulina Powder and Soybean Meal on Juvenile Rainbow Trout (Oncorhynchus mykiss Walbaum). Israeli J. Aquaculture-Bamidgeh 64, 790.

Fry, J. P., Mailloux, N. A., Love, D. C., Milli, M. C., and Cao, L. (2018). Feed Conversion Efficiency in Aquaculture: Do We Measure it Correctly? Environ. Res. Lett. 13 (2), 024017. doi:10.1088/1748-9326/aaa273

Fuma, S., Une, Y., Ihara, S., Matsui, K., Kudo, T., Tokiwa, T., et al. (2014). Effects of Chronic $\gamma$-irradiation on Growth and Survival of the Tohoku Hynobiid Salamander, Hynobius Lichenatus. J. Environ. Radioactivity 135, 84-92. doi:10.1016/j.jenvrad.2014.04.001

Gagnaire, B., Cavalié, I., Pereira, S., Floriani, M., Dubourg, N., Camilleri, V., et al. (2015). External Gamma Irradiation-Induced Effects in Early-Life Stages of Zebrafish, Danio rerio. Aquat. Toxicol. 169, 69-78. doi:10.1016/ j.aquatox.2015.10.005

Galasso, H. L., Lefebvre, S., Aliaume, C., Sadoul, B., and Callier, M. D. (2020). Using the Dynamic Energy Budget Theory to Evaluate the Bioremediation Potential of the Polychaete Hediste Diversicolor in an Integrated Multi-Trophic Aquaculture System. Ecol. Model. 437, 109296. doi:10.1016/ j.ecolmodel.2020.109296

Galès, A., Triplet, S., Geoffroy, T., Roques, C., Carré, C., Le Floc'h, E., et al. (2020). Control of the $\mathrm{pH}$ for marine Microalgae Polycultures: A Key point for $\mathrm{CO} 2$ Fixation Improvement in Intensive Cultures. J. Co2 Utilization 38, 187-193. doi:10.1016/j.jcou.2020.01.019

Ganuza, E., Benítez-Santana, T., Atalah, E., Vega-Orellana, O., Ganga, R., and Izquierdo, M. S. (2008). Crypthecodinium Cohnii and Schizochytrium Sp. As Potential Substitutes to Fisheries-Derived Oils from Seabream (Sparus aurata) Microdiets. Aquaculture 277 (1-2), 109-116. doi:10.1016/j.aquaculture.2008.02.005

Gonzales, J. M. (2009). Aquaculture in Bio-Regenerative Life Support Systems (BLSS): Considerations. Adv. Space Res. 43 (8), 1250-1255. doi:10.1016/ j.asr.2009.01.034

Gonzales, J. M., and Brown, P. B. (2007). Nutrient Retention Capabilities of Nile tilapia (Oreochromis niloticus) Fed Bio-Regenerative Life Support System (BLSS) Waste Residues. Adv. Space Res. 40 (11), 1725-1734. doi:10.1016/ j.asr.2007.06.034

Gregory, M. K., Collins, R. O., Tocher, D. R., James, M. J., and Turchini, G. M. (2016). Nutritional Regulation of Long-Chain PUFA Biosynthetic Genes in Rainbow trout (Oncorhynchus mykiss). Br. J. Nutr. 115 (10), 1721-1729. doi:10.1017/s0007114516000830

Gretebeck, R. J., Siconolfi, S. F., Rice, B., and Lane, H. W. (1994). Physical Performance Is Maintained in Women Consuming Only Foods Used on the U.S. Space Shuttle. Aviat Space Environ. Med. 65 (11), 1036-1040.

Guo, Z., Phooi, W. B. A., Lim, Z. J., and Tong, Y. W. (2015). Control of CO2 Input Conditions during Outdoor Culture of Chlorella Vulgaris in Bubble Column Photobioreactors. Bioresour. Technol. 186, 238-245. doi:10.1016/ j.biortech.2015.03.065

Häder, D.-P., Richter, P. R., Strauch, S. M., and Schuster, M. (2006). Aquacells Flagellates under Long-Term Microgravity and Potential Usage for Life Support Systems. Microgravity Sci. Technol. 18 (3-4), 210-214. doi:10.1007/bf02870411

Handeland, S. O., Imsland, A. K., and Stefansson, S. O. (2008). The Effect of Temperature and Fish Size on Growth, Feed Intake, Food Conversion Efficiency and Stomach Evacuation Rate of Atlantic salmon post-smolts. Aquaculture 283 (1-4), 36-42. doi:10.1016/j.aquaculture.2008.06.042

Hanson, J. (1983). Ecology, Aquaculture and Space Colonies. Proc. OCEANS 83, 998-1001. doi:10.1109/OCEANS.1983.1152020

Hoffman, R. B., Salinas, G. A., and Baky, A. A. (1977). Behavioral Analyses of Killifish Exposed to Weightlessness in Apollo-Soyuz Test Project Aviation. Space Environ. Med. 48 (8), 712-717.

Honda, Y., Honda, S., Narici, M., and Szewczyk, N. J. (2014). Spaceflight and Ageing: Reflecting onCaenorhabditis Elegansin Space. Gerontology 60 (2), 138-142. doi:10.1159/000354772

Ibsch, M., Anken, R. H., and Rahmann, H. (2000). Weightlessness during Spaceflight Results in Enhanced Synapse Formation in a Fish Brain Vestibular Nucleus. Neurosci. Lett. 296 (1), 13-16. doi:10.1016/s03043940(00)01594-9 
Ijiri, K. (1998). Development of Space-Fertilized Eggs and Formation of Primordial Germ Cells in the Embryos of Medaka Fish. Adv. Space Res. 21 (8), 1155-1158. doi:10.1016/s0273-1177(97)00205-6

Ijiri, K., Mizuno, R., and Eguchi, H. (2003). "Use of an Otolith-Deficient Mutant in Studies of Fish Behavior in Microgravity," in Space Life Sciences: Gravitational Biology: 2002. Editors L. L. Bruce, K. Ijiri, and G. Perbal, 32, 1501-1512. doi:10.1016/s0273-1177(03)90388-7

Ishimatsu, A., Hayashi, M., and Kikkawa, T. (2008). Fishes in high-CO2, Acidified Oceans. Mar. Ecol. Prog. Ser. 373, 295-302. doi:10.3354/meps07823

Kalousová, K., Souček, O., Tobie, G., Choblet, G., and Čadek, O. (2016). Water Generation and Transport below Europa's Strike-Slip Faults. J. Geophys. Res. Planets 121 (12), 2444-2462. doi:10.1002/2016je005188

Khodadad, C. L. M., Hummerick, M. E., Spencer, L. E., Dixit, A. R., Richards, J. T., Romeyn, M. W., et al. (2020). Microbiological and Nutritional Analysis of Lettuce Crops Grown on the International Space Station. Front. Plant Sci. 11, 199. doi:10.3389/fpls.2020.00199

Kicklighter, C., Kubanek, J., Barsby, T., and Hay, M. (2003). Palatability and Defense of Some Tropical Infaunal Worms: Alkylpyrrole Sulfamates as Deterrents to Fish Feeding. Mar. Ecol. Prog. Ser. 263, 299-306. doi:10.3354/ meps263299

Kiron, V., Phromkunthong, W., Huntley, M., Archibald, I., and Scheemaker, G. (2012). Marine Microalgae from Biorefinery as a Potential Feed Protein Source for Atlantic salmon, Common Carp and Whiteleg Shrimp. Aquacult. Nutr. 18 (5), 521-531. doi:10.1111/j.1365-2095.2011.00923.x

Kiss, J. Z. (2014). Plant Biology in Reduced Gravity on the Moon and Mars. Plant Biol. J. 16, 12-17. doi:10.1111/plb.12031

König, B., Dünne, M., and Slenzka, K. (2001). "Earth Life Support for Aquatic Organisms, System and Technical Aspects," in Space Life Sciences: Closed Ecological Systems: Earth and Space Applications. Editor M. Nelson, 27, 1523-1528. doi:10.1016/s0273-1177(01)00259-9

Koutnik, A. P., Favre, M. E., Noboa, K., Sanchez-Gonzalez, M. A., Moss, S. E., Goubran, B., et al. (2021). Human Adaptations to Multiday Saturation on NASA NEEMO. Front. Physiol. 11. doi:10.3389/fphys.2020.610000

Lasseur, C., Verstraete, W., Gros, J. B., Dubertret, G., and Rogalla, F. (1996). "MELISSA: A Potential experiment for a Precursor mission to the Moon," in Missions to the Moon and Exploring the Cold Universe. Editors B. H. Foing, R. H. Manka, and D. Lemke, 18, 111-117. doi:10.1016/0273-1177(96)00097-x

Leys, N., Baatout, S., Rosier, C., Dams, A., s'Heeren, C., Wattiez, R., et al. (2009). The Response of Cupriavidus Metallidurans $\mathrm{CH} 34$ to Spaceflight in the International Space Station. Antonie van Leeuwenhoek 96 (2), 227-245. doi:10.1007/s10482-009-9360-5

Li, M., Callier, M. D., Blancheton, J.-P., Galès, A., Nahon, S., Triplet, S., et al. (2019). Bioremediation of Fishpond Effluent and Production of Microalgae for an Oyster Farm in an Innovative Recirculating Integrated Multi-Trophic Aquaculture System. Aquaculture 504, 314-325. doi:10.1016/ j.aquaculture.2019.02.013

Liu, H., Yu, C. Y., Manukovsky, N. S., Kovalev, V. S., Gurevich, Y. L., and Wang, J. (2008). A Conceptual Configuration of the Lunar Base Bioregenerative Life Support System Including Soil-like Substrate for Growing Plants. Adv. Space Res. 42 (6), 1080-1088. doi:10.1016/j.asr.2008.03.020

Liu, L.-g. (2019). Origin and Early Evolution of Terrestrial Planet Atmospheres and Oceans. Terr. Atmos. Ocean. Sci. 30 (6), 765-770. doi:10.3319/tao.2019.05.08.01

Lychakov, D. V. (2016). Behavioural and Functional Vestibular Disorders after Space Flight: 2. Fish, Amphibians and Birds. J. Evol. Biochem. Phys. 52 (1), 1-16. doi:10.1134/s0022093016010014

Marques, R., Bouvier, C., Darnaude, A. M., Molinero, J.-C., Przybyla, C., Soriano, S., et al. (2016). Jellyfish as an Alternative Source of Food for Opportunistic Fishes. J. Exp. Mar. Biol. Ecol. 485, 1-7. doi:10.1016/j.jembe.2016.08.008

McCubbin, F. M., and Barnes, J. J. (2019). Origin and Abundances of $\mathrm{H} 2 \mathrm{O}$ in the Terrestrial Planets, Moon, and Asteroids. Earth Planet. Sci. Lett. 526, 115771. doi:10.1016/j.epsl.2019.115771

Mladineo, I., Bočina, I., Przybyla, C., Fievet, J., and Blancheton, J.-P. (2010). Fish Growth and Health Aspects of Sea Bass (Dicentrarchus labrax) Reared in Standard vs. High Rate Algal Pond Recirculation Systems. Aquat. Living Resour. 23 (2), 217-224. doi:10.1051/alr/2010013

Morais, S., Mourente, G., Martínez, A., Gras, N., and Tocher, D. R. (2015). Docosahexaenoic Acid Biosynthesis via Fatty Acyl Elongase and $\Delta 4$ desaturase and its Modulation by Dietary Lipid Level and Fatty Acid
Composition in a marine Vertebrate. Biochim. Biophys. Acta (Bba) - Mol. Cel Biol. Lipids 1851 (5), 588-597. doi:10.1016/j.bbalip.2015.01.014

Mori, S., Mitarai, G., Takabayashi, A., Usui, S., Sakakibara, M., Nagatomo, M., et al. (1996). Evidence of Sensory Conflict and Recovery in Carp Exposed to Prolonged Weightlessness. Aviat Space Environ. Med. 67 (3), 256-261.

Mori, S., Mitarai, G., Takagi, S., Takabayashi, A., Usui, S., Nakamura, T., et al. (1994). Space experiment Using Large-Sized Fish. Acta Astronautica 33, 41-47. doi:10.1016/0094-5765(94)90107-4

Murata, Y., Yasuda, T., Watanabe-Asaka, T., Oda, S., Mantoku, A., Takeyama, K., et al. (2015). Histological and Transcriptomic Analysis of Adult Japanese Medaka Sampled Onboard the International Space Station. Plos One 10 (10), e0138799. doi:10.1371/journal.pone.0138799

Niederwieser, T., Kociolek, P., and Klaus, D. (2018). A Review of Algal Research in Space. Acta Astronautica 146, 359-367. doi:10.1016/j.actaastro.2018.03.026

Niihori, M., Mogami, Y., Naruse, K., and Baba, S. A. (2004). Development and Swimming Behavior of Medaka Fry in a Spaceflight Aboard the Space Shuttle Columbia (STS-107). Zoolog. Sci. 21 (9), 923-931. doi:10.2108/zsj.21.923

Olson, S. L., Jansen, M., and Abbot, D. S. (2020). Oceanographic Considerations for Exoplanet Life Detection. ApJ 895 (1), 19. doi:10.3847/1538-4357/ab88c9

Olvera-Novoa, M. A., Domínguez-Cen, L. J., Olivera-Castillo, L., and MartínezPalacios, C. A. (1998). Effect of the Use of the Microalga Spirulina Maxima as Fish Meal Replacement in Diets for tilapia, Oreochromis mossambicus (Peters), Fry. Aquacult. Res. 29 (10), 709-715. doi:10.1046/j.1365-2109.1998.29100709.x

Orosei, R., Lauro, S. E., Pettinelli, E., Cicchetti, A., Coradini, M., Cosciotti, B., et al. (2018). Radar Evidence of Subglacial Liquid Water on Mars. Science 361 (6401), eaar7268-493. doi:10.1126/science.aar7268

Pagand, P., Blancheton, J.-P., Lemoalle, J., and Casellas, C. (2000). The Use of High Rate Algal Ponds for the Treatment of marine Effluent from a Recirculating Fish Rearing System. Aquacult. Res. 31 (10), 729-736. doi:10.1046/j.13652109.2000.00493.x

Palmegiano, G. B., Agradi, E., Forneris, G., Gai, F., Gasco, L., Rigamonti, E., et al. (2005). Spirulina as a Nutrient Source in Diets for Growing sturgeon (Acipenser Baeri). Aquac. Res. 36 (2), 188-195. doi:10.1111/j.13652109.2005.01209.x

Palmer, P. J., Wang, S., Houlihan, A., and Brock, I. (2014). Nutritional Status of a Nereidid Polychaete Cultured in Sand Filters of Mariculture Wastewater. Aquacult Nutr. 20 (6), 675-691. doi:10.1111/anu.12129

Paradiso, R., Buonomo, R., De Micco, V., Aronne, G., Palermo, M., Barbieri, G., et al. (2012). Soybean Cultivar Selection for Bioregenerative Life Support Systems (BLSSs) - Hydroponic Cultivation. Adv. Space Res. 50 (11), 1501-1511. doi:10.1016/j.asr.2012.07.025

Perez-Pascual, D., Estelle, J., Dutto, G., Rodde, C., Bernardet, J. F., Marchand, Y., et al. (2020). Growth Performance and Adaptability of European Sea Bass (Dicentrarchus labrax) Gut Microbiota to Alternative Diets Free of Fish Products. Microorganisms 8 (9):1346 doi:10.3390/microorganisms8091346

Poughon, L., Farges, B., Dussap, C. G., Godia, F., and Lasseur, C. (2009). Simulation of the MELiSSA Closed Loop System as a Tool to Define its Integration Strategy. Adv. Space Res. 44 (12), 1392-1403. doi:10.1016/j.asr.2009.07.021

Praveen Kumar, M. K., Shyama, S. K., Kashif, S., Dubey, S. K., Avelyno, D., Sonaye, B. H., et al. (2017). Effects of Gamma Radiation on the Early Developmental Stages of Zebrafish (Danio rerio). Ecotoxicol Environ. Saf. 142, 95-101. doi:10.1016/j.ecoenv.2017.03.054

Przybyla, C., Fievet, J., Callier, M., and Blancheton, J.-P. (2014). Effect of Dietary Water Content on European Sea Bass (Dicentrarchus labrax) Growth and Disease Resistance. Aquat. Living Resour. 27 (2), 73-81. doi:10.1051/alr/2014007

Quinton, R. (1912). L'eau de mer, milieu organique. Paris: Masson et Cie. Editeurs. doi:10.5962/bhl.title.16370

Rahmann, H., and Anken, R. H. (2002). "Gravity Related Research with Fishes Perspectives in Regard to the Upcoming International Space Station, ISS," in Space Life Sciences: Biological Research and Space Radiation. Editors K. Ijiri, K. Slenzka, and A. Kronenberg, 30, 697-710. doi:10.1016/s0273-1177(02) 00384-8

Sarma, A. P., Petar, P., and Murthy, S. D. S. (2008). Spirulina as a Source of Single Cell Protein. Vegetos 21 (1), 35-45.

Sebastian, C., Esseling, K., and Horn, E. (2001). Altered Gravitational Forces Affect the Development of the Static Vestibuloocular Reflex in Fish (Oreochromis mossambicus). J. Neurobiol. 46 (1), 59-72. doi:10.1002/1097-4695(200101)46: $1<59$ ::aid-neu6 $>3.0 . c 0 ; 2-\mathrm{x}$ 
Simon, O., Massarin, S., Coppin, F., Hinton, T. G., and Gilbin, R. (2011). Investigating the Embryo/larval Toxic and Genotoxic Effects of $\gamma$ Irradiation on Zebrafish Eggs. J. Environ. Radioactivity 102 (11), 1039-1044. doi:10.1016/ j.jenvrad.2011.06.004

Stein, T. P. (2001). Nutrition in the Space Station Era. Nutr. Res. Rev. 14 (1), 87-118. doi:10.1079/095442201108729150

Stuart, K. R., Barrows, F. T., Silbernagel, C., Alfrey, K., Rotstein, D., and Drawbridge, M. A. (2021). Complete Replacement of Fish Oil and Fish Meal in the Diet of Juvenile California Yellowtail Seriola Dorsalis. Aquac. Res. 52 (2), 655-665. doi:10.1111/are.14923

Tacon, A. G. J., Lemos, D., and Metian, M. (2020). Fish for Health: Improved Nutritional Quality of Cultured Fish for Human Consumption. Rev. Fish. Sci. Aquacult. 28 (4), 449-458. doi:10.1080/23308249.2020.1762163

Tibaldi, E., Chini Zittelli, G., Parisi, G., Bruno, M., Giorgi, G., Tulli, F., et al. (2015). Growth Performance and Quality Traits of European Sea Bass (D. labrax) Fed Diets Including Increasing Levels of Freeze-Dried Isochrysis Sp. (T-ISO) Biomass as a Source of Protein and N-3 Long Chain PUFA in Partial Substitution of Fish Derivatives. Aquaculture 440, 60-68. doi:10.1016/j.aquaculture.2015.02.002

Tikhomirov, A. A., Ushakova, S. A., Kovaleva, N. P., Lamaze, B., Lobo, M., and Lasseur, C. (2007). Biological Life Support Systems for a Mars mission Planetary Base: Problems and Prospects. Adv. Space Res. 40 (11), 1741-1745. doi:10.1016/j.asr.2006.11.009

Tocher, D. R. (2015). Omega-3 Long-Chain Polyunsaturated Fatty Acids and Aquaculture in Perspective. Aquaculture 449, 94-107. doi:10.1016/ j.aquaculture.2015.01.010

Trout, O. F., Trout, J., and Bruchey, W. J., Jr. (1969). Water Immersion ReducedGravity Simulation. Hum. Factors 11 (5), 473-487. doi:10.1177/ 001872086901100507

Tulli, F., Chini Zittelli, G., Giorgi, G., Poli, B. M., Tibaldi, E., and Tredici, M. R. (2012). Effect of the Inclusion of DriedTetraselmis Suecicaon Growth, Feed Utilization, and Fillet Composition of European Sea Bass Juveniles Fed Organic
Diets. J. Aquat. Food Product. Technol. 21 (3), 188-197. doi:10.1080/ 10498850.2012.664803

Verseux, C., Baqué, M., Lehto, K., de Vera, J.-P. P., Rothschild, L. J., and Billi, D. (2016). Sustainable Life Support on Mars - the Potential Roles of Cyanobacteria. Int. J. Astrobiology 15 (1), 65-92. doi:10.1017/s147355041500021x

Walker, A. B., and Berlinsky, D. L. (2011). Effects of Partial Replacement of Fish Meal Protein by Microalgae on Growth, Feed Intake, and Body Composition of Atlantic Cod. North Am. J. Aquacult. 73 (1), 76-83. doi:10.1080/ 15222055.2010.549030

Yang, L., Li, H., Liu, T., Zhong, Y., Ji, C., Lu, Q., et al. (2019). Microalgae Biotechnology as an Attempt for Bioregenerative Life Support Systems: Problems and Prospects. J. Chem. Technol. Biotechnol. 94 (10), 3039-3048. doi:10.1002/jctb.6159

Zabel, P., Bamsey, M., Schubert, D., and Tajmar, M. (2016). Review and Analysis of over 40 Years of Space Plant Growth Systems. Life Sci. Space Res. 10, 1-16. doi:10.1016/j.lssr.2016.06.004

Zeidler, C., Vrakking, V., Bamsey, M., Poulet, L., Zabel, P., Schubert, D., et al. (2017). Greenhouse Module for Space System: A Lunar Greenhouse Design. Open Agric. 2 (1), 116-132. doi:10.1515/opag-2017-0011

Conflict of Interest: The author declares that the research was conducted in the absence of any commercial or financial relationships that could be construed as a potential conflict of interest.

Copyright (C) 2021 Przybyla. This is an open-access article distributed under the terms of the Creative Commons Attribution License (CC BY). The use, distribution or reproduction in other forums is permitted, provided the original author(s) and the copyright owner(s) are credited and that the original publication in this journal is cited, in accordance with accepted academic practice. No use, distribution or reproduction is permitted which does not comply with these terms. 